Check for updates

Cite this: RSC Adv., 2021, 11, 16216

Received 25th January 2021

Accepted 25th April 2021

DOI: $10.1039 / \mathrm{d} 1 \mathrm{ra00637a}$

rsc.li/rsc-advances

\title{
Synthesis and characterization of nanoceria for electrochemical sensing applications
}

\author{
Yeni Wahyuni Hartati, (D) *a Seda Nur Topkaya, (D) ${ }^{\text {b }}$ Shabarni Gaffar, ${ }^{a}$ Husein H. Bahtia \\ and Arif E. Cetin (D)
}

Nanoceria (cerium oxide nanoparticles: $\mathrm{CeO}_{2}-\mathrm{NPs}$ ) has received significant attention due to its biocompatibility, good conductivity, and the ability to transfer oxygen. Nanoceria has been widely used to develop electrochemical sensors and biosensors as it could increase response time, sensitivity, and stability of the sensor. In this review, we discussed synthesis methods, and the recent applications employing $\mathrm{CeO}_{2}$-NPs for electrochemical detection of various analytes reported in the most recent four years.

\section{Introduction}

Cerium is a member of the lanthanide metals, including bastnäsite, allanite, cerite, monazite, euxenite, and xenotime), and it is the most abundant of rare-earth metals found in Earth's crust. ${ }^{1}$ Oxide of cerium is called ceria, and has two oxidation states $\mathrm{Ce}^{4+}\left(\mathrm{CeO}_{2}\right)$ and $\mathrm{Ce}^{3+}\left(\mathrm{Ce}_{2} \mathrm{O}_{3}\right) \cdot \mathrm{CeO}_{2}$ has a cubic fluorite structure, where each $\mathrm{Ce}^{+}$cation is surrounded by 8 oxygen anions, and each anion has a $\mathrm{Ce}^{+}$tetrahedral cation. ${ }^{2}$ Oxidation potentials and numbers of electronegative oxygen atoms are related to their ability to interact with biomacromolecules, e.g., proteins, nucleic acids, and others in specific medium. ${ }^{3}$

Cerium(Iv) oxide is also known as cerium dioxide, ceria oxide, ceria dioxide and ceria, and has been widely used as an antibacterial agent, biosensor, catalyst, fluorescent material, and for agricultural applications. ${ }^{4-7}$ Nanoceria is a cerium oxide with a size between 1 and $100 \mathrm{~nm}$, and has diverse applications such as sensors and drug delivery ${ }^{\mathbf{8}, 9}$ due to its attractive properties, e.g., biocompatibility, chemical and thermal stability,
${ }^{a}$ Department of Chemistry, Faculty of Mathematics and Natural Sciences, Universitas Padjadjaran, Indonesia. E-mail: yeni.w.hartati@unpad.ac.id

${ }^{b}$ Department of Analytical Chemistry, Faculty of Pharmacy, Izmir Katip Celebi University, Turkey
'Izmir Biomedicine and Genome Center, Izmir, Turkey

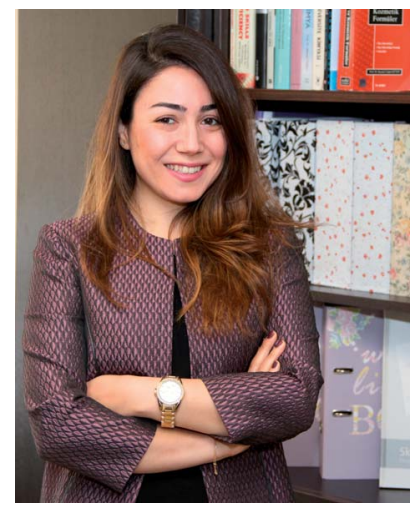

Seda Nur Topkaya completed her PhD in 2013 in Analytical Chemistry, Faculty of Pharmacy at Ege University, Turkey. She is an Associate Professor in Analytical Chemistry and the head of both Basic Pharmaceutical Sciences and the Department of Analytical Chemistry at Izmir Katip Celebi University. Her main research interests are electrochemistry, biosensors, drug-biomolecule interactions, electrochemical-based DNA biosensors and tissue engineering applications. She has published more than 30 papers in SCI indexed journals and served as reviewer-editorial board member of numerous international journals. 
high oxygen storage capacity, good superficial electrical diffusivity, and conductivity. ${ }^{\mathbf{1 0 - 1 2}}$ Nanoceria can be also used for transducers thanks to its high sensitivity. ${ }^{13-15}$ The interaction between adsorbed molecules and the cerium oxide surface is dependent on crystal surface and plane properties of the nanoceria. For instance, spherical crystalline nanoceria electrodes show higher discharge capacity than carbonaceous electrode. ${ }^{\mathbf{1 6}}$ Physicochemical properties of nanoparticles depend on the synthesis methods, e.g., different methods have been used to produce nanoceria in different morphology such as size, shape, distribution, and agglomeration. In nanoceria synthesis, various precursors have been used, e.g., raw materials such as cerium nitrate, cerium chloride, cerium sulphate which are then converted to cerium oxide. ${ }^{17}$

Physicochemical properties of nanoceria play an important role in the ultimate interaction with bioreceptors, target cells, and others chemical or biochemical species. Physicochemical and surface properties of nanoceria, e.g., synthesis methods controlling their biological activity as an inactive, antioxidant, or pro-oxidant, have reviewed in detailed. ${ }^{18} \mathrm{~A}$ comparative

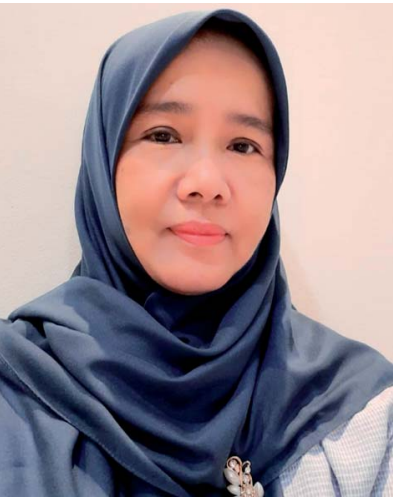
degree in Biochemistry from Institut Teknologi Bandung, Indonesia in 1998, and her doctoral degree in Biochemistry from Faculty of Mathematics and Natural Sciences, Universitas Padjadjaran in 2011. She joined the Department of Chemistry, Universitas Padjadjaran as a lecturer in 2005. Since 2015 she has collaborated with Dr Yeni $W$. Hartati with research focusing on electrochemical DNA biosensors, immunosensors and aptasensors.

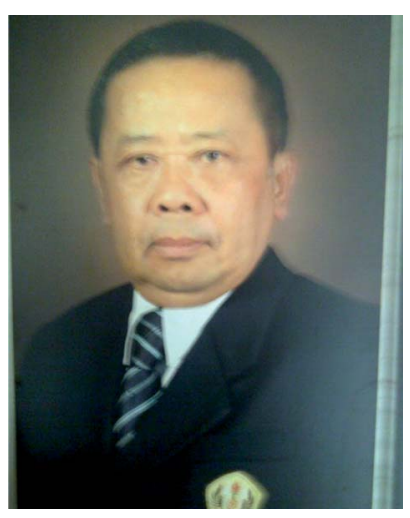

Husein H. Bahti is a Professor in the Department of Chemistry, Faculty of Mathematics and Natural Sciences, Padjadjaran University, Indonesia. His doctor degree was received in 1991 from the School of Chemistry, University of New South Wales, Australia. In 1997 Husein did a post doct. at Cambridge University, UK. Working in one of the Research Groups in the Department of Chemistry, the research interests of Husein and his junior staff has been in the separation, purification and production of rare-earth elements, and their use in the development of functional materials, to include voltammetric sensors, magnetic resonance imaging contrast agents, and catalysts. evaluation on photocatalytic efficiencies with physicochemical properties of nanoceria, ${ }^{19}$ toxicity effect, ${ }^{20}$ adsorption of metals onto nanoceria, and biosensing applications with nanoceria have been also performed in various reviews in literature.

In this paper, synthesis and characterization methods, and applications of nanoceria for electrochemical bio-detection of various analytes reported in the last four years (2017-2020) were reviewed.

\section{Synthesis of nanoceria}

Synthesis of nanoceria can be carried out by various physical and chemical processes such as precipitation, hydrothermal, sol-gel, solvothermal, and green synthesis. Different methods can produce nanoceria with different forms, shapes, patterns, and sizes. Correlation of nanoceria between physical and chemical properties, as well as their sizes and surface morphologies is extremely important for controllable synthesis of nanocrystals with specific dimensions and shapes. Sensing capability of nanoceria is also strongly dependent on its shape and size.

Chemical and physical methods are effective, and have faster synthesis time than biological processes. However, these methods have some disadvantages, e.g., the use of hazardous chemicals which can generate toxic waste, while the physical methods are energy intensively, expensive, and harmful to the environment. In addition, nanomaterials employed in these methods need to modified for biocompatibility. Green synthesis becomes a popular method for the synthesis of nanomaterials, including nanoceria. Recently, various natural extracts have been used as bio-reductant and chelating agent. Furthermore, plant extracts, algae, fungi and bacteria can be used for the biosynthesis of nanoceria. Nanoparticles produced through green synthesis exhibit enhanced biocompatibility compared to physically or chemically synthesized ones as they are naturally reduced and stabilized by plant phytochemicals. ${ }^{21}$ However, the use of extracts except plants have limitation regarding to

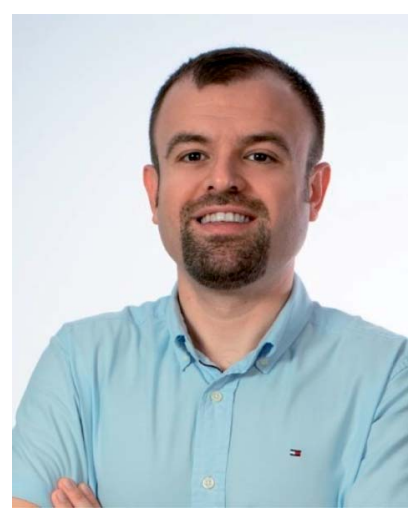

Arif E. Cetin is a Research Group Leader in Izmir Biomedicine and Genome Center in Izmir, Turkey. $H e$ received his $P h D$ degree from Boston University, Boston, MA. He worked as a postdoctoral associate at EPFL, Switzerland and MIT, Massachusetts, MA and research scientist at Omniome Inc. San Diego, CA, USA. Dr Cetin pursues research on optical nano-biosensors integrated with microfluidics, handheld biosensors for high-throughput and multiplexed biosensing, electromechanical sensors for growth rate cytometry, and label-free techniques for DNA sequencing. 
biosafety concerns, and need sterile conditions and maintenance of microbial cultures. Therefore, plants are preferred for extraction by providing a simple platform for green synthesis method of nanoparticles.

\subsection{Precipitation method}

Precipitation is very favorable technique due to its simplicity for synthesizing nanoceria at room or high temperature. The process does not require washing and purification steps. Cerium nitrate hexahydrate is mostly used as precursors for nanoceria synthesis under alkaline conditions, e.g., aqueous ammonia or sodium hydroxide were used..$^{22-24}$ Process of nanocrystal formation is carried out at room temperature, while calcining at various temperatures.

Nanoceria could be synthesized from cerium nitrate hexahydrate with poly(ethylene)imine (PEI) as a complexing agent and sodium salt of carboxy-methylated poly(ethylene)imine (Trilon P) as a dispersing agent. ${ }^{25}$ A precipitation method was developed with the use of cerium nitrate hexahydrate with poly vinyl pyrrolidone (PVP), poly vinyl alcohol (PVA), and ammonia as precursors. ${ }^{26}$

Cerium(III) chloride heptahydrate with ammonium hydroxide can form ceria nanorods, through a stirring procedure. ${ }^{27,28}$ Cerium sulphate was used as a precursor in basic conditions, e.g., ammonia water ${ }^{29}$ and sodium hydroxide. ${ }^{30}$ Matin et al. performed calcination at two different temperatures, where the shape, size, and distribution of nanoceria strongly influence the surface properties. ${ }^{29}$ Ultrasound assistedprecipitation in the synthesis of ceria nanoparticles could be achieved via the reduction of cerium nitrate hexahydrate at room temperature. Different solvents have been used, e.g., methanol, ethylene glycol, water, and isopropyl alcohol, without the addition of a capping agent. Cerium nitrate hexahydrate was dissolved in distilled water and sodium hydroxide was added drop wise under sonication. The mixture was then irradiated with sonication, and nanoceria could be synthesized in the size of $4-8 .^{31}$

\subsection{Hydrothermal method}

Hydrothermal method is the most preferred method for the synthesis of metals, metal oxides, and metal composites with variety of crystalline morphologies. It involves hydrolysis of metal salt using water as solvent, and condensation of metal hydroxide to produce ultrafine metal or metal oxide particles. ${ }^{24}$ Chemical reactions usually occur in under pressure. Particles in desired size and shape can be produced in hydrothermal process with the control of parameters, e.g., $\mathrm{pH}$, reaction time, temperature, type of solvent and solute concentration. Nanoceria could be synthesized with hydrothermal method using various precursors of cerium salts with particular modifications, i.e., different morphologies of nanoceria have been developed. For instance, ceria nanorods were synthesized from cerium hexahydrate and urea with surfactant-free hydrothermal approach. ${ }^{32}$ Single crystalline mesoporous cerium oxide nanospheres were produced with $\mathrm{CeCO}_{3} \mathrm{OH}$ by controlling the amount of urea as a structural directing agent. ${ }^{33}$ Shape-specific nanoceria synthesized via hydrothermal method with cerium nitrate as precursors were precisely controlled by molarity of sodium hydroxide, reaction temperature, and $\mathrm{pH}^{34-37}$ Addition of surfactants as a stabilizer agent can also control the overall shape of nanomaterials, and have critical roles on surface adsorption of surface active molecules. An 8-20 nm ceria nanocubes have been synthesized with cerium nitrate (precursor), and ammonia with TritonX-100 (surfactant). ${ }^{38}$ In another approach, adjusting $\mathrm{pH}$ of $\mathrm{CeCl}_{3}$ solution was realized by ammonia, e.g., a white precipitate was formed to produce $40 \mathrm{~nm}$ nanoceria. ${ }^{39}$ An ultrasonic-assisted hydrothermal method was applied to produce ceria nanorods using cerium. At low $\mathrm{pH}$, samples consist of nanoparticles, while at high $\mathrm{pH}$, rod length increased, e.g., cerium oxide nanorods were formed. Furthermore, $\mathrm{Ce}(\mathrm{OH})_{3}$ nuclei were formed right after $\mathrm{Ce}^{3+}$ ions were mixed with $\mathrm{NaOH}$ solution. ${ }^{40}$

\subsection{Combustion method}

Solution combustion synthesis combines combustion synthesis and reactive solution. Typically, a reaction of an oxidizer (usually metal nitrates) and a fuel cause releasing of large amounts of gases and heat. Fuels can be classified based on their type of reactive groups, e.g., hydroxyl, amino, and carboxyl. Fuel-to-oxidizer ratio is one important parameter for determining stoichiometry and the morphology of the nanoparticles. Cerium nitrate hexahydrate (oxidizer) and nanoceria (precursor) reacted with glycine (fuel) under various conditions in ammonium nitrate that produced 6-30 $\mathrm{nm}$ nanoceria. ${ }^{41,42}$ The reaction of ceria formation from cerium nitrate with ammonium nitrate and glycine under combustion reaction could be written as $\mathrm{Ce}\left(\mathrm{NO}_{3}\right)_{3} \cdot 6 \mathrm{H}_{2} \mathrm{O}_{(\mathrm{aq})}+2 \mathrm{C}_{2} \mathrm{H}_{5} \mathrm{O}_{2} \mathrm{~N}_{(\mathrm{aq})}+\mathrm{NH}_{4} \mathrm{NO}_{3(\mathrm{aq})} \nrightarrow \mathrm{CeO}_{2(\mathrm{~s})}+$ $4 \mathrm{CO}_{2(\mathrm{~g})}+13 \mathrm{H}_{2} \mathrm{O}+7 / 2 \mathrm{~N}_{2(\mathrm{~g})}$. The aqueous solution containing redox mixture in glassware then was heated to $150{ }^{\circ} \mathrm{C}$, e.g., after boiling, foams undergoes combustion with a flame to produce ceria. ${ }^{43}$ Solution combustion method was used for synthetizing nanoceria with cerium nitrate (precursor) and urea (fuel), where the resulting cerium oxide nanoparticles were in the form of sphere with the sizes in the range between 10-15 $\mathrm{nm}^{\mathbf{4 4}}$

\subsection{Decomposition and microwave-assisted heating method}

In this method, precursor of nanoparticles are dissolved in organic solvents with the addition of stabilizer, and heated until the decomposition temperature. Stabilizer was added to bind the nucleus of nanoparticles, i.e., it prevents aggregation of nanoparticles. Type of precursors, solvent, stabilizer, reaction temperature and heating time control the quality of nanoparticles. Direct thermal decomposition of cerium(III) nitrate hexahydrate and ammonium bicarbonate precursors have been carried out without solvents to synthesize nanoceria. After drying at room temperature, the mixture was annealed in a furnace at between $200-300{ }^{\circ} \mathrm{C}$ with rate of temperature rise step of $10^{\circ} \mathrm{C} \mathrm{min}^{-1}$ and $13 \mathrm{~nm}$ ceria crystal was produced. ${ }^{45}$ Another precursor, e.g., cerium oxalate decahydrate was also used for synthesizing nanoceria. Dehydration reaction was performed at $150{ }^{\circ} \mathrm{C}$ causing anisotropic changes in the crystals dimensions, and fast coarsening of crystallites started at $500{ }^{\circ} \mathrm{C}$. 
Average size of nanoceria crystallites was between $4-5 \mathrm{~nm}^{46}$ Cerium carbonate hydrate precursors was also used to synthesize spherical nanoceria particles via decomposition method in $\mathrm{KOH}-\mathrm{NaOH}$ molten mixture. $\mathrm{CeCO}_{3} \mathrm{OH}$ was used as an initial material placed in a crucible with a muffle furnace at between $200-700{ }^{\circ} \mathrm{C}$ to produce $22-55 \mathrm{~nm}$ nanoceria. ${ }^{47}$

Synthesis of dispersible nanoceria was achieved by simple solvent free thermolysis route. The cerium oleate precursor was prepared from cerium nitrate salt and sodium oleate. Cerium oleate powders were heated at $320{ }^{\circ} \mathrm{C}$ for different periods of time. The decomposed product was dissolved in hexane and sonicated gently to produce colloidal ceria nanoparticles. ${ }^{48}$ The nanocrystallite cerium oxide powders were also prepared from precursor nanopowders by thermal decomposition. The Ce-propionate powder precursor was prepared by dissolved cerium(III) acetate sesquihydrate in the methanol : propionic acid (with a $1: 2$ ratio), stirring at $60{ }^{\circ} \mathrm{C}$, then dried at $120{ }^{\circ} \mathrm{C}$ in air. ${ }^{49}$

Synthesize of nanoceria by microwave-assisted heating control resulted in high quality of nanoparticles by optimizing parameters reaction. Microwave irradiation could promote synthesis of cerium oxide nanoparticles. He et al. compared the characteristics of nanoceria synthesized with cerium nitrate hexahydrate used as precursor in microwave-assisted heating control with traditional thermal methods and. Here, the core of nanoceria had similar crystal structures, where the particle size was slightly smaller. This process is less reactive to variation of redox environment compared to microwave-assisted heating methods. ${ }^{50}$ Microwave-assisted procedure was also carried out to prepare nanoceria with narrow size distribution without any serious agglomeration. In this method, precursors were cerium nitrate, where sodium hydroxide solution were placed in a microwave oven and the end products were dried in a vacuum oven at $60{ }^{\circ} \mathrm{C}$ to produce $7 \mathrm{~nm}$ nanoceria. ${ }^{51}$

\subsection{Oxidation and wet synthesis method}

Oxidation method is directed using a suitable oxidizing agent to synthesize nanoparticles. In general, this method uses cerium nitrate hexahydrate as precursor, and cerium(III) ion was oxidized to cerium(Iv) using excess hydrogen peroxide $\left(\mathrm{H}_{2} \mathrm{O}_{2}\right)$ as an oxidizer in acidic or basic aqueous media. Particle size of nanoceria decreases with oxidation concentration. Cerium salts was also used as precursors for preparation of nanoceria via wet oxidation synthesize procedures. Cerium(III) acetate hydrate, ceric ammonium nitrate, cerium chloride heptahydrate, cerium nitrate hexahydrate, and cerium sulphate octahydrate were oxidized with the aid of $\mathrm{H}_{2} \mathrm{O}_{2}$ to form homogeneous dispersion of $100 \mathrm{~nm}-5 \mu \mathrm{m}$ crystalline nanoceria. ${ }^{52}$ Oxidation technique and hydroxidefree method were also conducted to synthesize fluorite structured nanoceria using ozone and aliphatic alcohols at room-temperature. Nanoceria with an average size of $2 \mathrm{~nm}$ to $4 \mathrm{~nm}$ was generated using bubbling ozone into the alcohol cerium salt solutions. Possible pathways for the synthesis of nanoceria could be: (i) oxidation of alcohols into carboxylic acids mediated by ozone and cerium ions, (ii) oxidation of $\mathrm{Ce}^{3+}$ to $\mathrm{Ce}^{4+}$ by ozone in the presence of acids, and (iii) formation and decomposition of complex polymer network that was made from cerium ions, alcohols, and carboxylates into nanoceria. Fig. 1 shows the schematic of ozonation with ethanolic cerium(III) solution. ${ }^{53}$

\subsection{Solvothermal method}

Solvothermal method is a synthesis process using reaction in a solvent as liquid (or supercritical) medium at high temperatures. In this method, the solvent, e.g., water or organic compound, is heated until above its boiling point. The use of autoclaves (pressure vessels) is imperative for the reaction to proceed at high temperatures and under high pressures. In one study, nanoceria was prepared with cerium(III) nitrate as a source of cerium, and deionized water and alcohol to form cerium precursor solution. $\mathrm{H}_{2} \mathrm{O}_{2}$ and ammonia hydroxide were added into the solution, and all precipitates were mixed with anhydrous alcohol, transferred into a teflon-lined autoclave and heated. The method provided 4.8-10 nm nanoceria by filtering and vacuum freeze drying. ${ }^{54}$ A deep eutectic-solvothermal
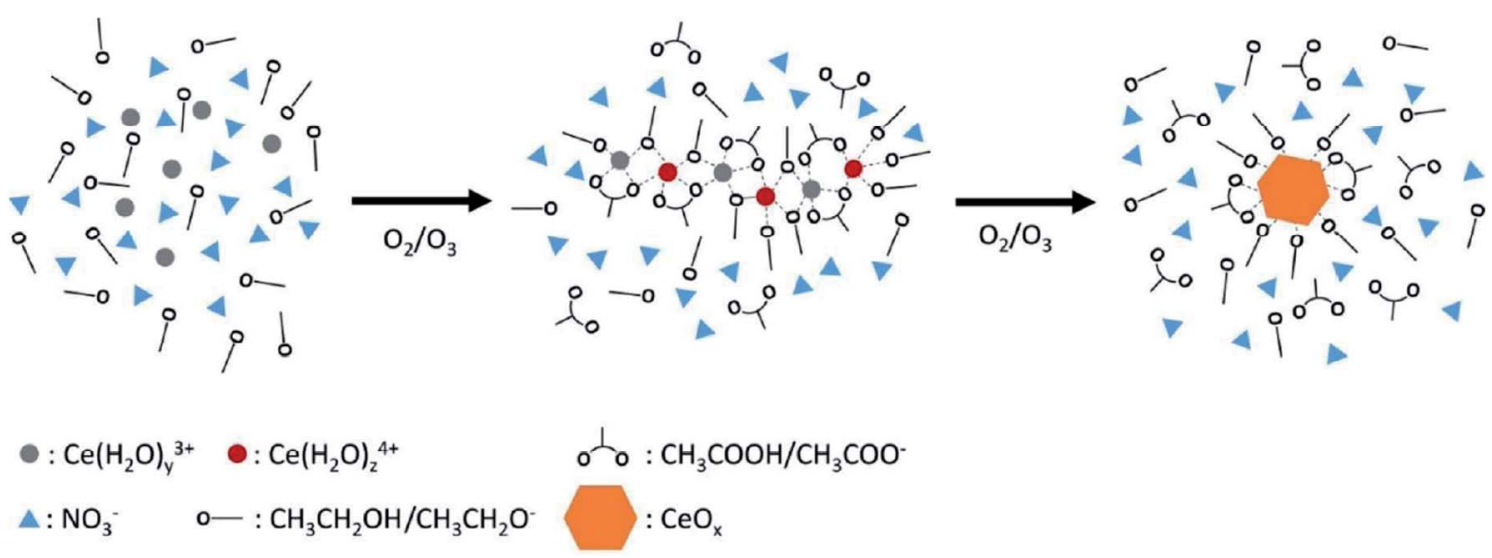

Fig. 1 Presentation of a reaction pathway for the synthesis of nanoceria in an ethanolic solution of cerium(III) nitrate via ozonation oxidation. Reprinted from ref. 47 with permission (c) Royal Society of Chemistry 2020. 
methodology has been developed to synthesize nanostructured ceria at low temperature. Deep eutectic solvents are green solvents that function as an ionic liquid realized by complexing ammonium halide salt with hydrogen bond donor molecules, depressing glass transition temperature $\left(T_{\mathrm{g}}\right)$ at the eutectic molar ratio. Hammond et al. demonstrated that reline (e.g., choline chloride) combined with urea acts as a latent supramolecular catalyst to bring reactive components together under water, where it acts as a directing agent in deep eutectic solvothermal methods. Reline and its aqueous mixtures are compatible with common ceria precursors, e.g., cerium nitrate hexahydrate or cerium chloride, eliminating the need for high concentration of solubilizing base required in equivalent hydrothermal synthesis. Significant number of short range associated cerium and nitrate ions were observed around choline and urea. Using this method, nanoceria with 5-20 nm size could be achieved. ${ }^{55}$

\subsection{Green synthesis method}

Green synthesis method has recently introduced as an ecofriendly and non-hazardous method (Fig. 2). This approach involves green synthesis of nanoceria, mediated by plants, fungus, nutrients, and biopolymers. Green synthesis of nanoceria with plant mediation has been realized using plant extracts which act as a stabilizing and capping agent. Cerium(III) chloride heptahydrate (precursor) was added to an aqueous extract of Aquilegia pubiflora at $60{ }^{\circ} \mathrm{C}$, centrifuged, oven-dried at $90{ }^{\circ} \mathrm{C}$, and finally calcined at $500{ }^{\circ} \mathrm{C}$. Extract of $A$ pubiflora contains phytochemicals, including flavonoids, e.g., vitexin and isovitexin, hydroxycinnamic acid derivatives, e.g., chlorogenic acid and ferulic acid as an effective reducing and capping agent. This approach could yield $28 \mathrm{~nm}$ nanoceria. Pisonia alba leaf extract with cerium chloride was also used as a capping agent in the green synthesis. ${ }^{56}$
Linum usitatissimum seed extract was used for nanoceria synthesis with an aqueous solution of cerium nitrate hexahydrate. Lu seeds contain phytochemical compounds such as phenolic acids, flavonoids, cinnamic acids, and lignin. These components have lone pair electrons that could coordinate cerium atoms as a capping agent. ${ }^{57}$ Salvia macrosiphon Boiss seed extract was also used for nanoceria synthesis which is rich with flavonoids, e.g., salvigenin, eupatorin, 13-epi-manoyl oxide, and sitosterol as capping agents. Hyphaene thebaica fruit, Ceratonia siliqua, Clitoria ternatea, Azadirachta indica leaves, Agathosma betulina flower, onion extracts, and ripe Morus nigra fruit, containing stabilizer and capping agent, were other substances used for nanoceria synthesis. ${ }^{58-61}$ Polyphenolic tannic acid has been introduced as a stabilizing agent for cerium nitrate hexahydrate, with calcination at $400{ }^{\circ} \mathrm{C}$ and $600{ }^{\circ} \mathrm{C}$, yielding 7-13 nm nanoceria. ${ }^{62}$ In another work, Moringa oleifera leaf was to realize $\sim 10 \mathrm{~nm}$ nanoceria extracted from ammonium ceric nitrate. ${ }^{63}$ Nanoceria, $30 \mathrm{~nm}$ in size, was biosynthesized using an aqueous extract of aerial parts of Prosopis farcta and cerium nitrate hexahydrate. ${ }^{64}$ Cerium(Iv) sulphate was used as precursor in the synthesis using Ficus carica leaf extract yielding $10-20 \mathrm{~nm}$ nanoceria. ${ }^{65}$ An ultrasound-assisted green synthesis of nanoceria has been reported using a rich piperidine alkaloids leaf extract, Prosopis juliflora, with cerium chloride as precursor. Here, the solution was heated at $80{ }^{\circ} \mathrm{C}$, and kept in the microwave oven at $2450 \mathrm{MHz}$ for $10 \mathrm{~min}$, and a yellowish brown precipitate was powdered at $800{ }^{\circ} \mathrm{C}$ that yielded $3.7 \mathrm{~nm}$ nanoceria. ${ }^{66}$ Khorrami et al. used pullulan, a water-soluble polysaccharide that contains maltoriose as a stabilizing agent for nanoceria synthesis. Cerium nitrate hexahydrate solution was added to the pullulan solution at $60{ }^{\circ} \mathrm{C}$, and the obtained resin was heated at $400-600{ }^{\circ} \mathrm{C}$ to form nanoceria. ${ }^{67}$ The thermal decomposition of cerium alginate (precursor) was used for the synthesis. Negatively charged

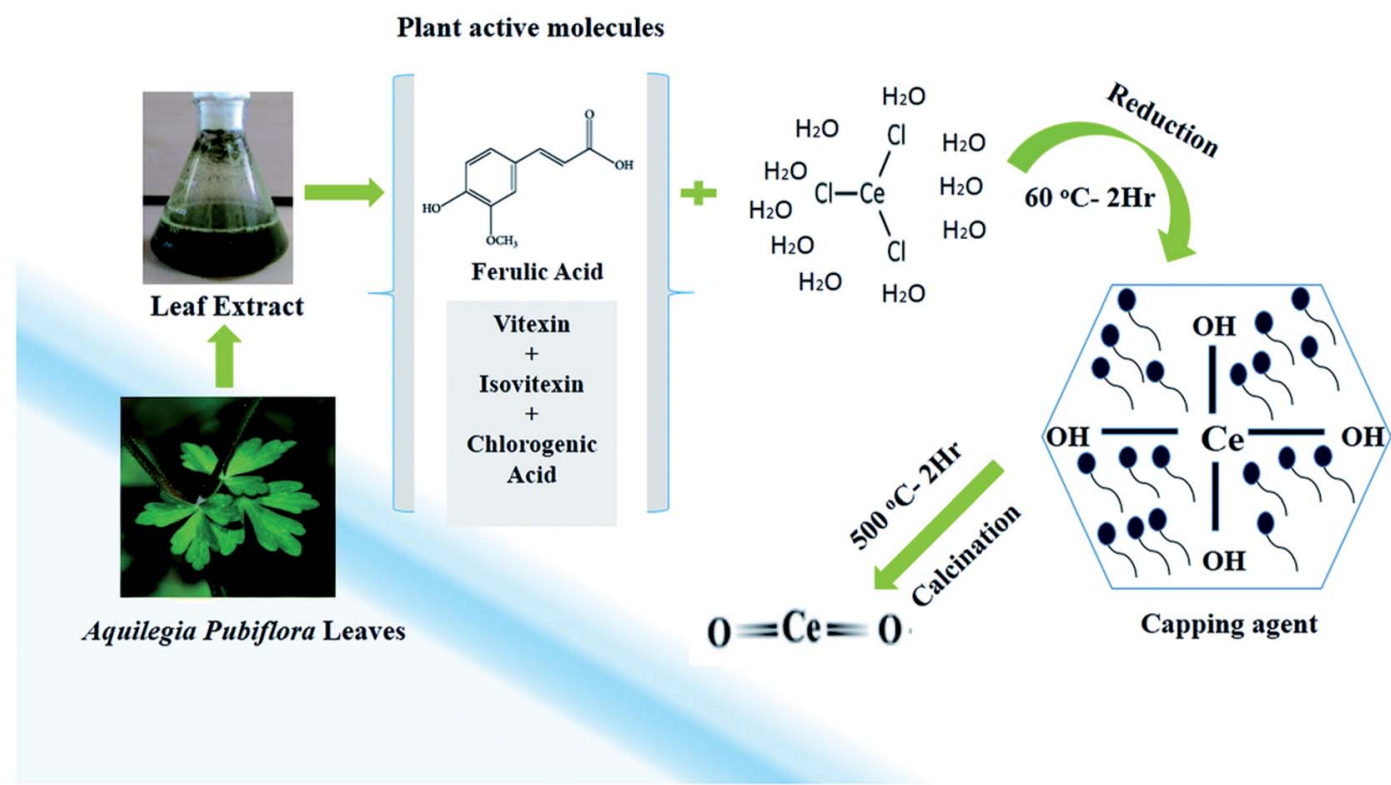

Fig. 2 Formation of nanoceria using Aquilegia pubiflora. Reprinted from ref. 51 with permission (c) Royal Society of Chemistry 2020. 
centres of alginate chains, e.g., carboxylate groups, bind to trivalent cation of cerium(III) forming a gel with 3-dimensional crosslinking. This method produces spherical nanoparticles with a size of $<5 \mathrm{~nm}$.

Cellulose was also used as a matrix of nano-biocomposites, where nanoceria is embedded in the matrix adopting solution plasma process (SPP), and an eco-friendly synthesis process. SPP-based chitosan-nanoceria does not aggregate or settle down as a pellet when subjected to centrifugation at $10000 \mathrm{rpm}$. This approach is very advantageous over the solvent based technique. ${ }^{68}$ In another work, nanoceria was prepared through a sol-gel method using biopolymeric chitosan as an organic template. Cerium nitrate was dispersed in deionized water, and added to the aqueous solution of chitosan. Cerium nitrate and chitosan solutions were mixed, and ammonium hydroxide solutions were added until $\mathrm{pH}$ is $\sim 10$, where mixture was stirred at $70{ }^{\circ} \mathrm{C}$ until a gel-like material was obtained. ${ }^{69}$ Chitosan-based synthesis was also reported for realizing nanoceria coupled with biocompatible ionic liquid. Here, chitosan was generated by deacetylation process of chitin from the shells of crab. Ionic liquid, 1-butyl-3methylimidazolium tetrafluoroborate, was used as thermal stabilizer and capping agent as well as surfactant to prevent agglomeration and aggregation of particles, effecting the morphology of nanoceria. ${ }^{69}$ The use of carrageenan hydrogel was used for eco-friendly preparation of nanoceria, where carrageenan forms a bond between polymeric chains to double helix domain through a temperature-induced sol-gel transition, and cerium ions anchor themselves to the $-\mathrm{SO}_{3}{ }^{-}$groups into carrageenan. After the gelation process, ceria has few space to escape from polymeric network, and the calcination at temperatures of $400-800{ }^{\circ} \mathrm{C}$ yielded nanoceria. ${ }^{69}$

\subsection{Other synthesis methods}

Flame spray pyrolysis method is used to synthesize particles through droplet aerosol formation process. Aerosols are small particles in the form of solids or liquids suspended in gas. Aerosol technology provides an alternative route for ceria synthesize with high surface area at high temperature. Particles in nanometer size are produced with flame spray pyrolysis utilizing atomization or spraying the solution into a flame above an atomization nozzle to produce powdered particles. Spray pyrolysis generally uses three types of atomizer to spray precursor into droplets, e.g., ultrasonic, mechanical, or electrospray. A flame spray pyrolysis method has been introduced to synthesize homogeneous nanoceria from xylene-dissolved liquid precursor, cerium 2-ethylhexanoate. ${ }^{70} \mathrm{~A}$ thermal treatment technique has been introduced which uses polyvinylpyrrolidone (capping agent) and deionized water (solvent), where calcination treatment was carried out at $500-650{ }^{\circ} \mathrm{C}$ to crystallize nanoceria. In this method, cerium nitrate hexahydrate was used as the precursor material. ${ }^{71} \mathrm{~A}$ modified polymer complex (PC) process was used to obtain nanoceria with high purity at low temperature. PC method successfully reduces individualities of different metal ions, achieved by encircling stable metal-chelate complexes via a growing polymer net. This rigid organic polymer net reduces segregation of particulate metals during the decomposition process of the polymer. ${ }^{72}$

Reverse micelle is another synthesis method, where cerium nitrate hexahydrate solution was mixed with colloidal micelle solution. Ammonium hydroxide solution was added into the mixture, and incubated until nanoceria slowly formed in the reversed micelles. Cerium oxide nanoparticles were rinsed with ethanol and water, centrifuged, collected, and dried at 50$60{ }^{\circ} \mathrm{C} .{ }^{73}$ Aqua phase nanoceria synthesis was performed via 6aminohexanoic acid (6-AHA). Cerium(III) nitrate solution was added continuously into an aqueous solution containing 6-AHA by using a syringe pump at $95^{\circ} \mathrm{C}$. The $2 \mathrm{D}$ self-organization ceria nanosheets were formed, which initially formed small ceria nanocrystals followed by an in situ recrystallization process. ${ }^{74}$ Colloidal synthesis strategy has developed for synthesis of ceria nanocubes with controlled morphology. Cerium nitrate, ammonium cerium nitrate, ammonia solution, and ammonium acetate are used as reactants operated under $80^{\circ} \mathrm{C}$. Existence of acetate radical ions is the critical factor in the formation of nanocubes ceria. ${ }^{75}$ Surfactant free-aerogel synthesis involves the preparation of sols of metal salts followed by gelation, and finally the exclusion of solvent by air to produce nanoceria. In this method, solvent can be excluded from gel by simple drying. In this method, nanoceria is produced with lesser capillary action, pore collapsing, low density, and high-surface-area. Cerium(III) nitrate hexahydrate and oxalic acid (precursor) and toluene-ethanol (solvent) mixture were used to obtain 3-5 nm nanoceria in size. ${ }^{76}$ Sol-gel method uses different solvents such as water, acetone, ethanol, and ethylene glycols, with cerium(III) nitrate hexahydrate, where ammonium hydroxide is used as precursors. $^{77}$

\section{Characterization studies}

Material characterization is a method for obtaining information on structure, composition, and defects of materials. Characterization provides information on the physical and chemical properties of the nanomaterials. Morphologies (size, shape and distribution) of nanoceria can be characterized by spectroscopic, microscopic, X-ray technique, and thermal stability methods. It is still challenging to determine physicochemical properties of nanoparticles and to explore their structurefunction relationships due to the fact that the nanoparticles are prone to agglomeration as well as they could have a broad distribution of sizes, shapes, and defects. These characteristics require comprehensive analysis of nanoparticle behavior. One important issue to consider is that the characterization methods can directly affect the measured nanoparticle quantities.

\subsection{UV-visible spectrophotometry}

UV-Visible characterization could be carried out to determine optical properties and the band gap energy of synthetized nanoceria. Absorption of nanoceria in the UV region arises due to the charge transition between $\mathrm{O}(2 \mathrm{p})$ and $\mathrm{Ce}(4 \mathrm{f})$ expressed in $\mathrm{O}^{2-}$ and $\mathrm{Ce}^{4+}$. In general, maximum absorption peak for 
nanoceria is observed between 290 and $360 \mathrm{~nm}$. Moreover, maximum absorption peak of nanoceria shifted towards lower wavelengths, which is associated with the quantum confinement effect due to the decrease in particle size. Band gap energy incorporated with the transition between valence and conduction band in ceria. Absorption of photons from UV-Vis spectrophotometry depends on the nature of the semiconductor material, and the wavelength of the incoming light. Absorption of a semiconductor material causes the excitation of electrons from the valence band to the conduction band. The band gap energy can be determined by Tauc plot method. The decrease in band gap energy can indicate larger nanoparticle sizes due to the increase in the crystallinity of nuclei $\mathrm{CeO}_{2}$ which forms a cluster, and becomes a dense and regular crystallite grain. ${ }^{78,79}$ Molten salt based methods were also developed using $\mathrm{KCl}-\mathrm{LiCl}$ to synthesize polyhedral nanoceria. Crystal structure of $\mathrm{Ce}_{2}\left(\mathrm{CO}_{3}\right)_{3} \cdot x \mathrm{H}_{2} \mathrm{O}$ broke down to crystal nuclei of nanoceria in the molten salt system. Fig. 3 shows the UV-Visible spectra of $\mathrm{KCl}-\mathrm{LiCl}$ salt system of nanoceria. Absorption peak of commercial nanoceria $\left(\mathrm{c}-\mathrm{CeO}_{2}\right)$ was centered at $308 \mathrm{~nm}$, whereas the molten salt product $\left(\mathrm{m}-\mathrm{CeO}_{2}\right)$ was found at $349 \mathrm{~nm}$. A significant red shift in the spectrum were observed, $\mathrm{m}-\mathrm{CeO}_{2}$ 's aged powder were found. Here, particle shape and the level of cerium species contribute these red or blue shift in the UV-Visible spectra, e.g., blue shift is due to the decrease in $\mathrm{Ce}^{4+}$ after the reduction reaction, while the red shift is due to the increase in $\mathrm{Ce}^{4+}$ after oxidation reaction. Lower band gap energy of m-corresponded to the lower of crystallinity $111(69.7 \%)$ and the higher strain percentage $(0.589 \%)$ of $\mathrm{m}-\mathrm{CeO}$ compared to $\mathrm{c}-\mathrm{CeO}_{2}$ (79.8 and $\left.0.389 \%\right)$. Different band gap also corresponded to the electronic transition, and depended on the methods of synthesis and particle size. ${ }^{\mathbf{8 0}}$ The effect of calcined temperatures of nanoceria synthesis resulted in a red shift in the UV-Visible spectra. This phenomenon corresponded to the increase in annealing temperature enhancing the crystalline properties. UV-Vis absorption ability of crystalline nanoceria depends on the band gap energy, e.g., high band gap energy enhances the interactions for smaller nanoparticles. ${ }^{\mathbf{4 4}}$

\subsection{Fourier transform infrared (FTIR) spectroscopy}

FTIR spectroscopy is a strong tool to identify different types of molecular bonds and functional groups, and to study the vibrational motion of atoms and molecules. Here, the spectrum peak at the frequency between 450 and $700 \mathrm{~cm}^{-1}$ corresponded to the O-Ce-O-vibration. Residual water and hydroxyl groups are detected in synthesized nanoceria (stretching vibration) at 1600, 1300, and between 3200 and $3400 \mathrm{~cm}^{-1}$. Wide bands at 1000, and between 1300 and $1400 \mathrm{~cm}^{-1}$ are related to the formation of carbonate-like groups on $\mathrm{CeO}_{2}$ surface. ${ }^{37,79}$ Effect of calcination temperature $\left(100{ }^{\circ} \mathrm{C}\right.$ and $\left.200{ }^{\circ} \mathrm{C}\right)$ of the synthesized nanoceria resulted in large IR absorption band at $500 \mathrm{~cm}^{-1}$ due to $\mathrm{Ce}-\mathrm{O}$ bond tension. In addition, the presence of $\mathrm{CeO}_{2}$ in the un-calcined specimen indicated by an absorption band at $840 \mathrm{~cm}^{-1}$ is a typical Ce-O stretching vibration. Peaks are observed at 1020,1050 , and $1100 \mathrm{~cm}^{-1}$ corresponding to calcined samples due to the interaction of cerium with $\mathrm{CO}_{2}$ resulting in $\mathrm{Ce}-\mathrm{O}-\mathrm{C}$ bonds stretching vibrations. ${ }^{29}$ Fig. 4 shows the IR spectra for nanoceria powders. The nanoceria was obtained at different $\mathrm{pH}$ values with pre-calcined at $350{ }^{\circ} \mathrm{C}$, and with heat treatment at $550{ }^{\circ} \mathrm{C}$. Vibrational modes of $\mathrm{Ce}-\mathrm{O}$ showed large band spectra between 400 and $630 \mathrm{~cm}^{-1}$. A broad band at $3450 \mathrm{~cm}^{-1}$ was associated with stretching vibration of O-H corresponding to the residual water or hydroxyl groups. The bands at 1300 and $950 \mathrm{~cm}^{-1}$ corresponded to the vibrational tension of $\mathrm{H}_{2} \mathrm{O}$. The variations in intensity at $\sim 1625 \mathrm{~cm}^{-1}$ is associated with $\mathrm{H}-\mathrm{OH}$ flexion that overlaps with the band corresponding to $\mathrm{O}-\mathrm{C}-\mathrm{O}$ stretching, following calcination. ${ }^{81}$

\subsection{Raman spectroscopy}

Raman spectroscopy is widely used method for studying structures, crystal defect, and films deposited on a particular substrate. In general, cerium oxide has a fluorite structure,
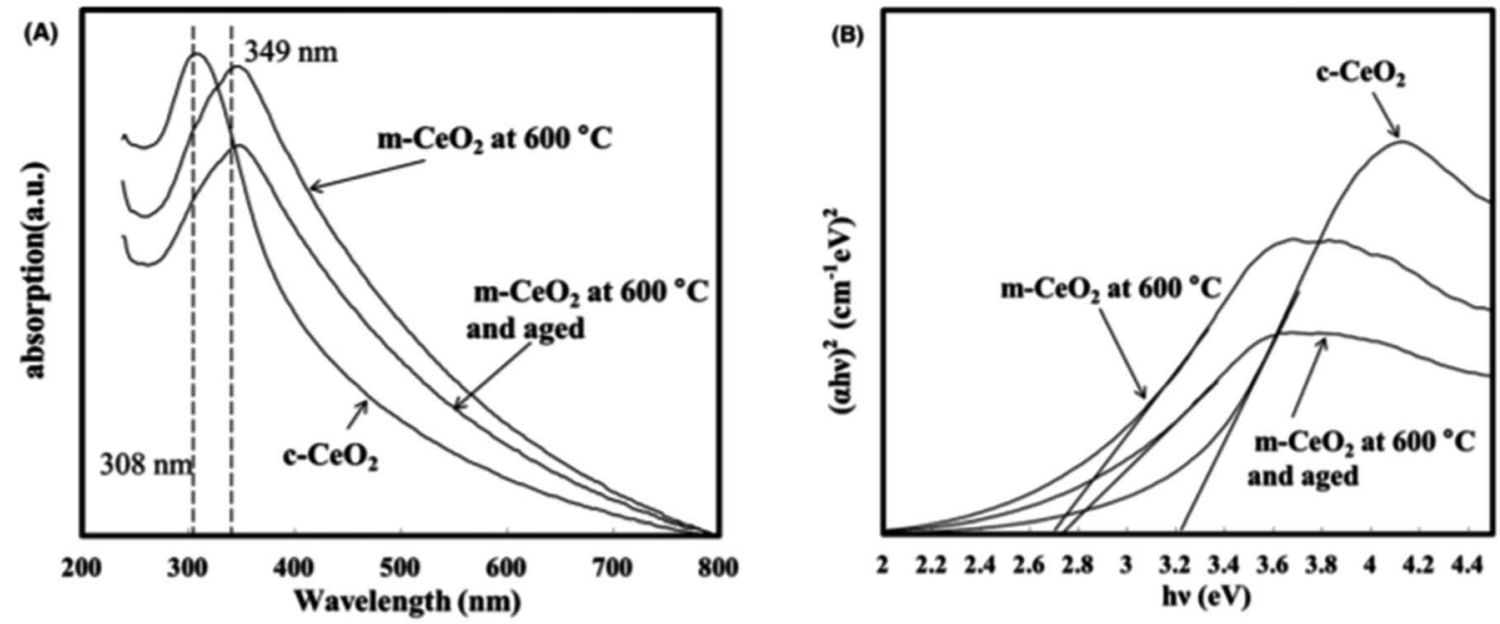

Fig. 3 (A) UV-Visible spectra of commercial nanoceria $\left(\mathrm{c}-\mathrm{CeO}_{2}\right)$, molten salt nanoceria synthesized $(\mathrm{m}-\mathrm{CeO})$ at $600{ }^{\circ} \mathrm{C}$, and $\mathrm{m}-\mathrm{CeO} 2$ aged, and (B) the dependence of $(\alpha h \nu)^{2}$ on photon energy $(h \nu)$. Reprinted from ref. 75 with permission @ 2017 The American Ceramic Society. 


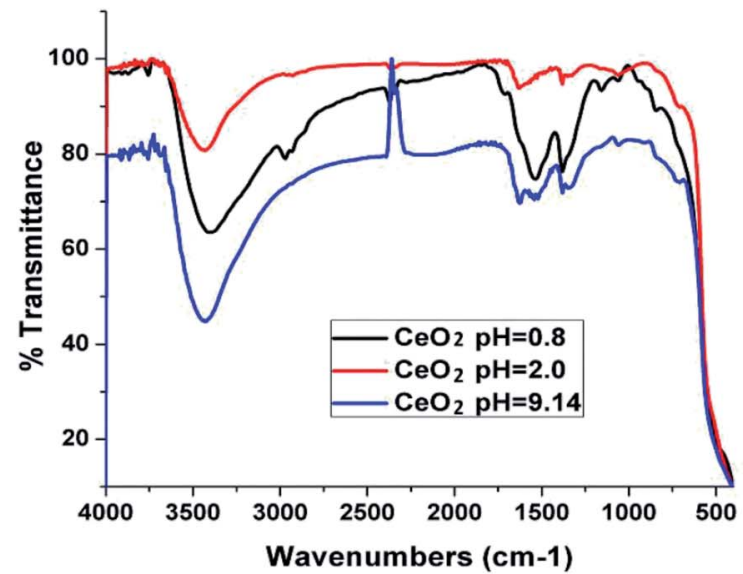

(a)

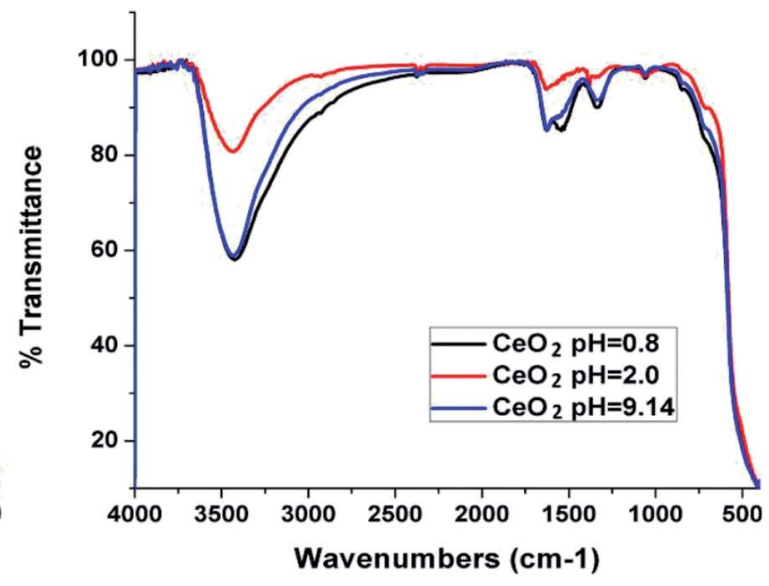

(b)

Fig. 4 IR spectra of nanoceria powders at different $\mathrm{pH}$ values (a) without heat treatment and (b) treated at $550{ }^{\circ} \mathrm{C}$. Reprinted from ref. 76 with permission @ 2020 Elsevier B.V.

which generates three peak frequencies, e.g., $272 \mathrm{~cm}^{-1}$ and $465 \mathrm{~cm}^{-1}$ corresponding to doubly and triply degenerate transverse optical mode, and $595 \mathrm{~cm}^{-1}$ related to non-generate longitudinal optical mode. Symmetric stretching at $460 \mathrm{~cm}^{-1}$ of $\mathrm{Ce}-\mathrm{O}$ incorporated with $\mathrm{F} 2 \mathrm{~g}$ vibrational mode of crystalline cubic fluorite type of ceria. ${ }^{82,83} \mathrm{Effect}$ of $\mathrm{pH}$ of nanoceria on the Raman spectra has been described. ${ }^{72}$ The spectrum obtained at $\mathrm{pH}=9.1$ showed bands at $1315,1430,1483$, and $1561 \mathrm{~cm}^{-1}$. The bands between 1300 and 1400 , and at $1560 \mathrm{~cm}^{-1}$ was associated with adsorbed $\mathrm{O}_{2}$. The system contained large amounts of carbon which favored reducing atmosphere, and thus the presence of $\mathrm{Ce}^{3+}$ below $550{ }^{\circ} \mathrm{C}$ during the synthesis of ceria. Carbon monoxide $(\mathrm{CO})$ and carbon dioxide $\left(\mathrm{CO}_{2}\right)$ can be also absorbed in the range between 1700 and $1800 \mathrm{~cm}^{-1}$ (bridged carbonate) and 1430 and $483 \mathrm{~cm}^{-1}$ (unidentate carbonate). Raman spectra were recorded between 410 and $520 \mathrm{~cm}^{-1}$, and between 1000 and $1400 \mathrm{~cm}^{-1}$ to show the effect of heat treatments on ceria samples synthesized at $\mathrm{pH}=2$.

In these spectra, amplitude and the spectral position of the bands at $\sim 460 \mathrm{~cm}^{-1}$ (symmetric mode of Raman vibration F2g), and at $1160 \mathrm{~cm}^{-1}$ (characteristic of the surface superoxide species, $\mathrm{O}_{2}^{-}$) changed. Fig. 5 shows the Raman spectra of the nanocubes (NC), nanorods (NR), and nano-octahedra (NO), submicronic octahedral (SO), and nanocubes + nanotruncated octahedral (NCO) of different sizes from hydrothermal process, in the range between Raman shift 350 and $700 \mathrm{~cm}^{-1}$. The strong peak at $460 \mathrm{~cm}^{-1}$ due to the $\mathrm{CeO}_{2}$ fluorite phase associated with a symmetric breathing of the oxygen atoms around cerium ions. This mode is size dependent and effected by irregularities in the sub lattice. This fact is shown in Fig. $5 \mathrm{~A}$, where $\mathrm{F} 2 \mathrm{~g}$ peak of the nanorods is broader compared to other morphologies. The weak peak around $600 \mathrm{~cm}^{-1}$ (denoted with D) shown in Fig. 5B was associated with oxygen defects, and due to the presence of Frenkel-type oxygen vacancies were an oxygen atom displaced from its lattice position to an interstitial site. ${ }^{82}$

\subsection{Photoluminescence spectra}

Photoluminescence (PL) is a photo induced fluorescence technique to investigate energy levels of materials. Violet emission peak at $477 \mathrm{~nm}$ and the green emission at $508 \mathrm{~nm}$ correspond to the surface defects. Multiple studies have been reported
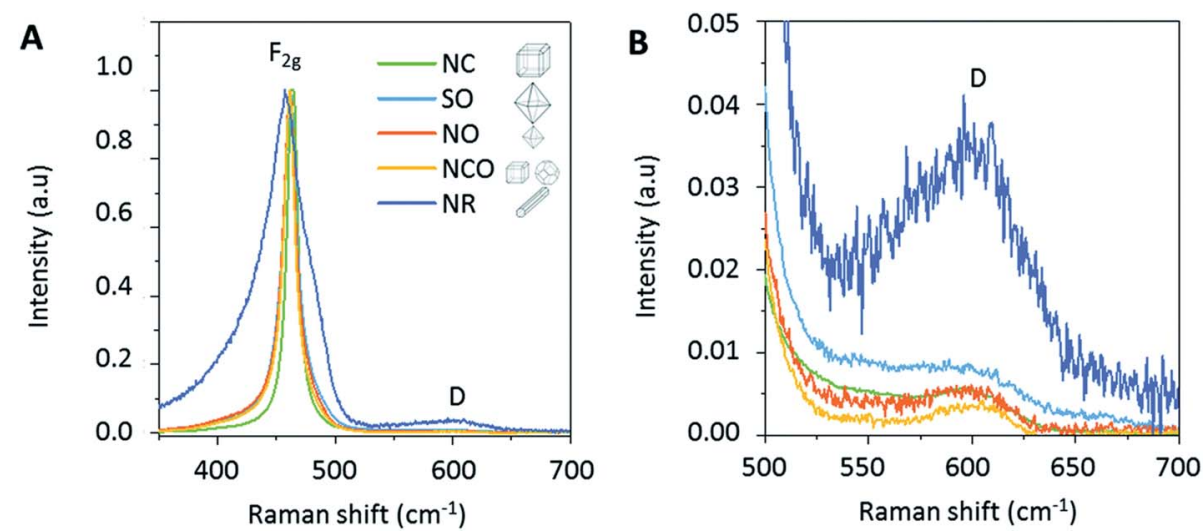

Fig. 5 (A) Raman spectra of $\mathrm{CeO}_{2}$ particles recorded in between 350 and $700 \mathrm{~cm}^{-1}$, and (B) between 500 and $700 \mathrm{~cm}^{-1}$, where excitation source is at $633 \mathrm{~nm}$. Reprinted from ref. 77 with permission (C) Royal Society of Chemistry 2020. 
showing that these peaks are associated with displaces or oxygen defects that contribute to oxygen vacancies at nanoceria. Electrons excited from the valence band to the $4 \mathrm{f}$ band of the oxide act as defects. The reduction in the $\mathrm{O}_{2}$ concentration increasing oxygen partial pressure resulted in the decrease within the peak intensity of PL spectra. ${ }^{84}$

\subsection{Scanning and transmission electron microscopy}

Scanning electron microscopy (SEM), field emission scanning electron microscopy (FESEM), transmission electron microscopy (TEM) are the fundamental tools to determine morphology
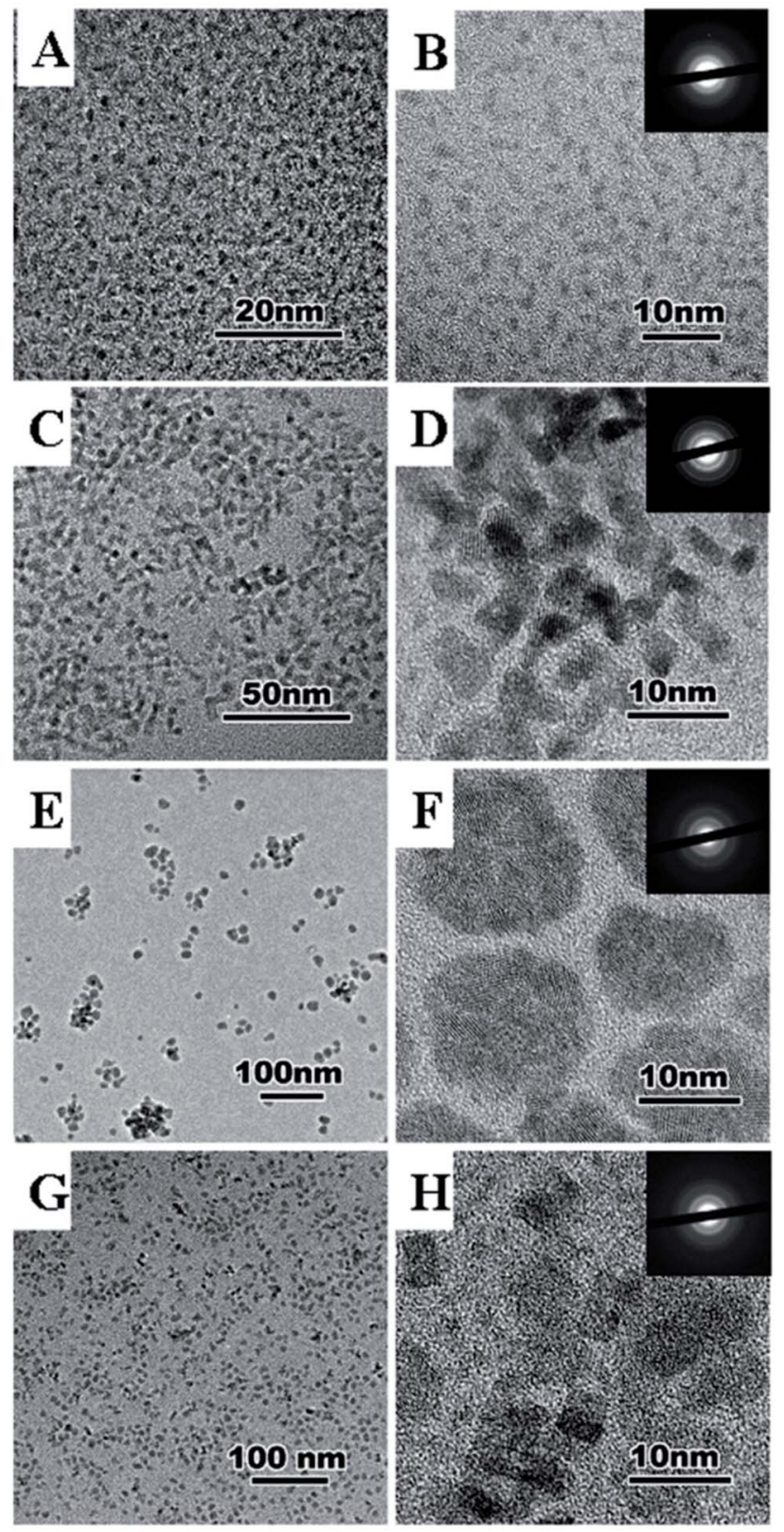

Fig. 6 TEM images of ceria nanoparticles synthesized by thermolysis of cerium oleate at $0.3 \mathrm{mbar}$ and $320^{\circ} \mathrm{C}$ for different reaction times: $0.7 \mathrm{~h}, 0.3 \mathrm{mbar}$ ( $\mathrm{A}$ and $\mathrm{B}$ ), $24 \mathrm{~h}, 0.3 \mathrm{mbar}$ ( $\mathrm{C}$ and $\mathrm{D}$ ), $72 \mathrm{~h}, 0.3 \mathrm{mbar}$ ( $\mathrm{E}$ and F), $144 \mathrm{~h}, 0.3 \mathrm{mbar}(\mathrm{G}$ and $\mathrm{H}$ ). Reprinted from ref. 42 with permission (C) Royal Society of Chemistry 2020. and size of the nanoparticles that results in image contrasts of the samples in nanoscale. SEM and TEM incorporated with energy dispersive X-ray spectroscopy (EDS or EDX) can provide elemental composition information of samples.

Here, the samples are shot with a high-energy electron beam which hit the sample, get reflected, and read by a detector. ${ }^{29,34}$ SEM and TEM images can distinguish agglomeration or decomposition of nanoparticle clusters. Fig. 6 shows representative TEM images for the nanoceria synthesized by thermolysis of cerium oleate at $0.3 \mathrm{mbar}$ and $320{ }^{\circ} \mathrm{C}$ for different times. Decomposition products of nanoceria based on decomposition time with different shapes and sizes were depicted clearly. Here, morphology (size, shape, distribution) of nanoceria growth is built by a nucleation dissolution recrystallization step mechanism, depending on the reaction time. ${ }^{48}$ Fig. $6 \mathrm{~A}$ and $\mathrm{B}$ show nanoceria with average size of $2 \mathrm{~nm}$ formed $0.7 \mathrm{~h}$ decomposition time. Fig. $6 \mathrm{C}$ and $\mathrm{D}$ show $8 \mathrm{~nm}$ rectangular single-crystal nanoceria for the decomposition time of $24 \mathrm{~h}$. Formation of $15 \mathrm{~nm}$ polycrystalline spherical nanoceria could be seen after the decomposition time increased to $72 \mathrm{~h}$ (Fig. $6 \mathrm{E}$ and F). $4 \mathrm{~nm}$ single crystalline nanoceria was obtained after $144 \mathrm{~h}$.

\subsection{X-ray diffraction}

$\mathrm{X}$-ray diffraction (XRD) is the method used to determine structure and the crystalline size of nanoceria. Average nano-crystalline size $(D)$ is calculated using the Scherrer formula; $D=K \lambda /$ $\beta \cos \theta$, where $D$ is the average crystallite size, $K$ is Scherer constant (0.9), $\lambda$ is the wavelength of the incident X-rays, $\beta=$ $\sqrt{ }\left(B_{2}-b_{2}\right)$, where $\beta$ is the full width at half maximum (FWHM) after correcting for instrumental broadening, $B$ is the observed FWHM of the film, $b$ is the instrumental broadening, and $\theta$ is the diffraction angle. ${ }^{83}$

Fig. 7 illustrates the XRD pattern of ceria nanoparticles in the range of angle $2 \theta$ between $5{ }^{\circ}$ and $80^{\circ}$. Nanoceria was synthesized by a low temperature water-based precipitation method. (111), (200), (220), (311), (222), (400), (311), and (331) peaks were obtained for the desired temperatures. These peaks are indexed to a pure cubic phase of $\mathrm{CeO}_{2-x}(0<x<0.5)$ with lattice constant $a=5.420 \AA$, according to The Joint Committee on Powder Diffraction Standards (JCPDS file no. 34-0394, space group

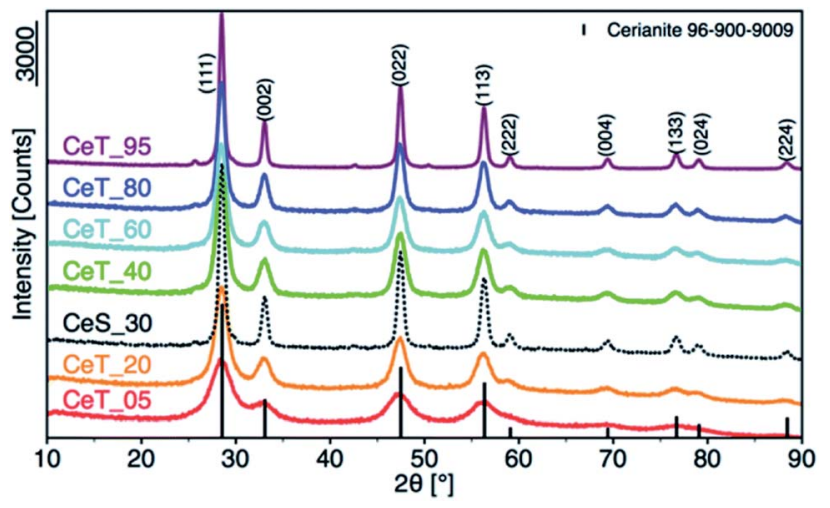

Fig. 7 XRD pattern of nanoceria synthesized at different reaction temperatures, e.g., 5, 20, 30, 40, 60, 80, and $95^{\circ} \mathrm{C}$. Reprinted from ref. 80 with permission @ The Royal Society of Chemistry 2020. 
Fm3m). XRD patterns show four main peaks, e.g., (111), (200), (220), and (311) of nanoceria that are well-defined and indicated correspond to the fluorite-type structure. The broadened peak corresponded to the nanometer-sized crystallites. The average crystallite size calculated with Scherer equation was found as between 2 and $15 \mathrm{~nm}^{\mathbf{8 5}}$

\subsection{X-ray photoelectron spectroscopy}

$\mathrm{X}$-ray photoelectron spectroscopy (XPS) is a non-destructive technique to investigate chemical and electronic structure of materials, and to characterize surface elemental composition. An important advantage of XPS is its ability to identify binding energies of the chemical shifts of elements, e.g., the shifts associated with the oxidation state of cerium in nanoceria. Matin et al. described XPS analysis of un-calcined and calcined precipitations nanoceria synthesis method. In this study, glass slides were coated with ceria particles, and a range of energies between 0 and $1000 \mathrm{eV}$ were used for identifying elements based on the binding energy survey scans. Next, high resolution scans were carried out to provide further details of lattice position and oxidation states. XPS spectra can exhibit the crystal structure of solid, e.g., a cubic, fluorite type for $\mathrm{Ce}^{4+}$ in $\mathrm{CeO}_{2}$, or a hexagonal structure such as sesquioxide type for $\mathrm{Ce}^{3+}$ in $\mathrm{Ce}_{2} \mathrm{O}_{3}$. Fig. 8 shows the surface elemental analysis using XPS for un-calcined and calcined nanoceria. Fig. 8a shows the FTIR spectra of the synthesized nanoparticles before and after the calcination at $100{ }^{\circ} \mathrm{C}$ and $200{ }^{\circ} \mathrm{C}$. Fig. $8 \mathrm{~b}$ and $\mathrm{c}$ shows the photoelectron peaks of cerium, e.g., Ce $3 \mathrm{~d}(\sim 900 \mathrm{eV})$ and Ce $4 \mathrm{~d}(110 \mathrm{eV})$, while $\mathrm{O} 1 \mathrm{~s}$ for oxygen due to the presence of elements detected on the surface of the coated substrates. In addition, C 1s $\sim 285 \mathrm{eV}$ confirmed the atmospheric contamination such as carbon that can interact with surface oxygen to form carbonates. Here, the peaks are also associated with the oxidation states, $\mathrm{Ce}^{3+}, \mathrm{Ce}^{4+}$, and lattice and non-lattice of oxygen. Fig. 8c also shows the minor differences in the spectra that are associated with temperature of calcination of nanoceria. Higher temperatures increase the proportion of carbon due to the contamination of hydrocarbons on the surface. Fig. 8d presents XPS high resolution scans for oxygen broken down into the lattice structure $(\sim 529 \mathrm{eV})$ at their regular site in nanoceria, and non-lattice oxygen atom $(\sim 531 \mathrm{eV})$ adsorbed onto the surface, e.g., hydroxyls or carbonates. ${ }^{29}$

\subsection{Thermogravimetric analysis}

Thermogravimetric analysis (TGA) is a technique for studying thermal behavior of the samples based on changes in chemical and physical properties in response to the changes of temperature. The change in sample mass at TGA is indicated as a function of temperature and time. Another thermal analysis is the differential thermal analysis (DTA) that measures the
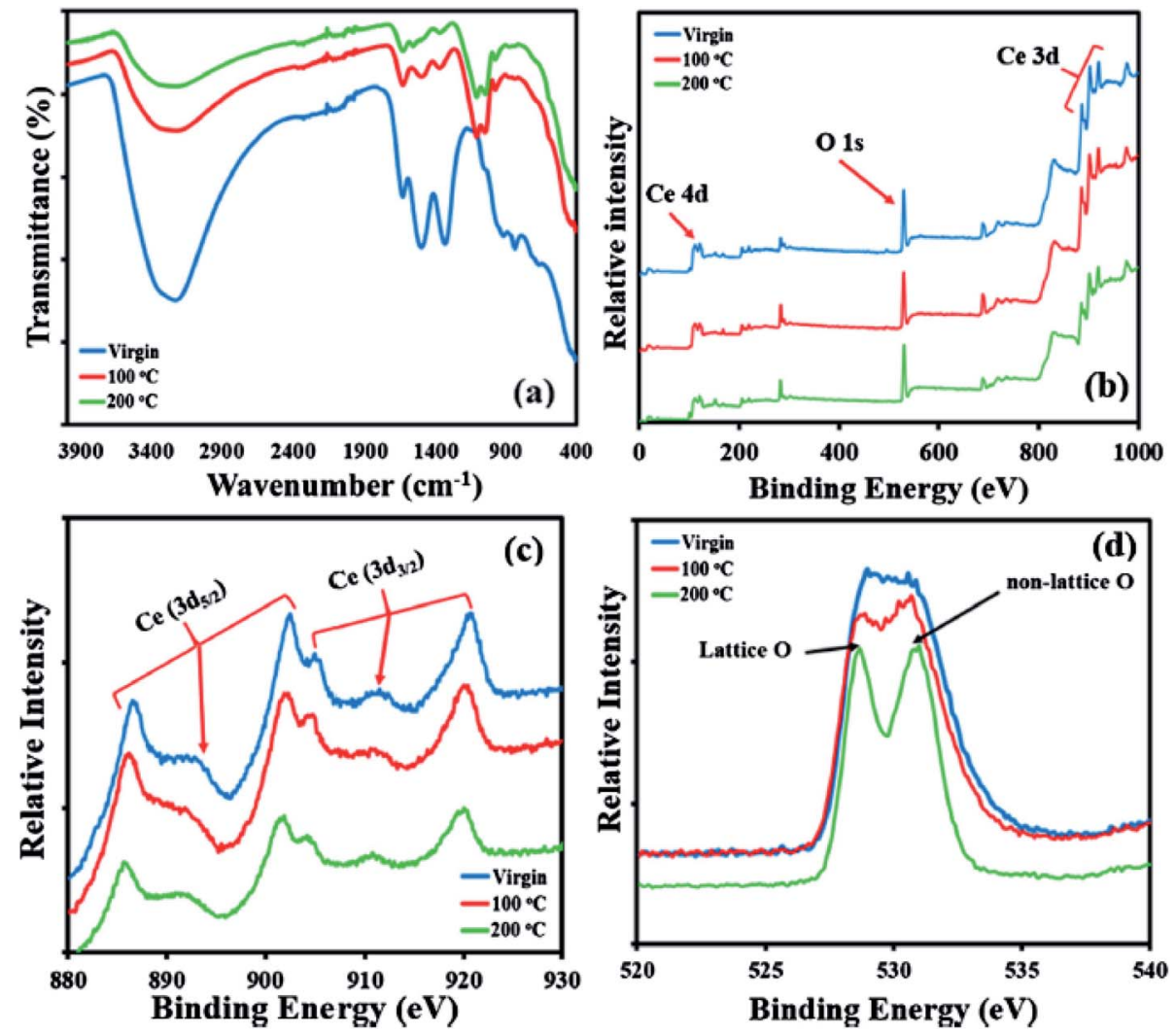

Fig. 8 Chemical composition of un-calcined and calcined ceria nanoparticles ( $a$ and b) using FTIR, and (c and d) and XPS. (a) FTIR spectra for all samples showing the presence of major $\mathrm{Ce}-\mathrm{O}$ bonding peaks. (b) XPS scans showing the presence of $\mathrm{Ce}$ and $\mathrm{O}$, with small amounts of $\mathrm{C}$ due to atmospheric contamination. (c) High-resolution scans for cerium showing the peaks belonging to the oxidation state of 4+. (d) Peaks for lattice oxygen and non-lattice oxygen that are visible at 529 and $531 \mathrm{eV}$ respectively. Reprinted from ref. 29 with permission (c) 2020 Elsevier B.V. 


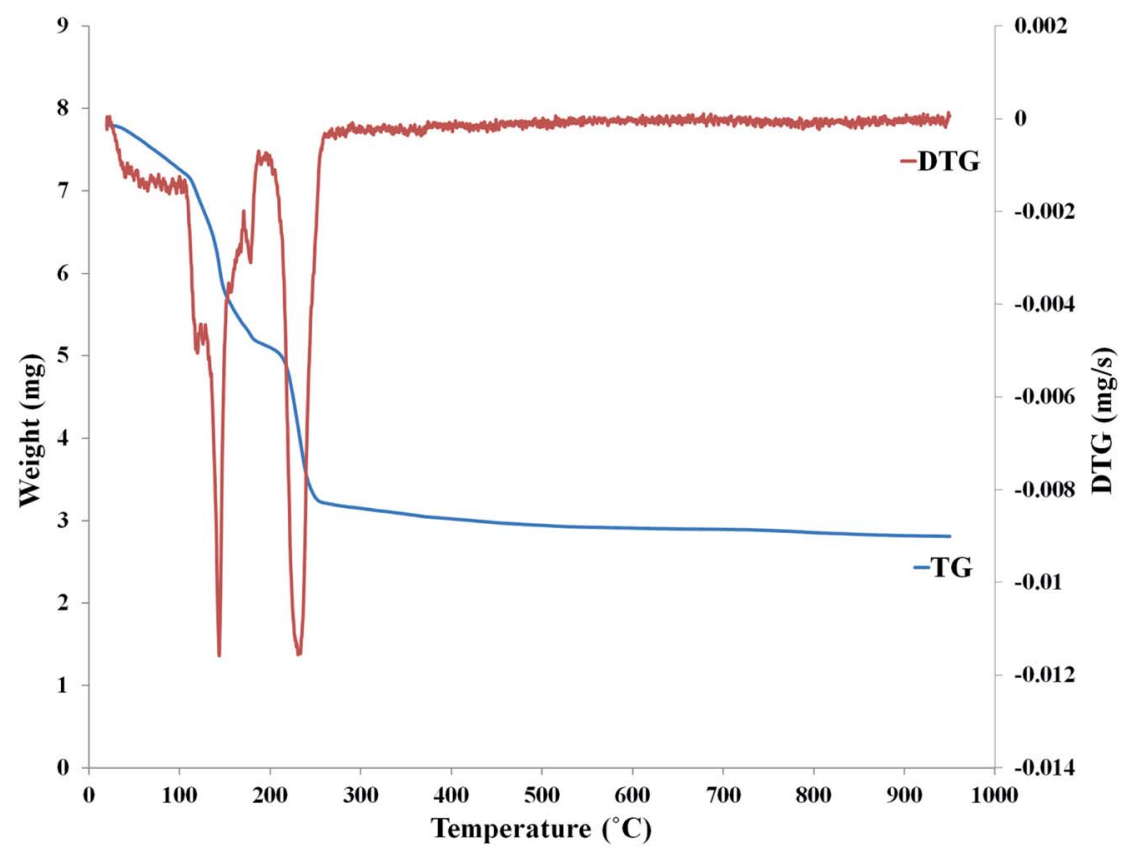

Fig. 9 TGA and DTG diagrams of nanoceria that was prepared with $30 \mathrm{~mL}$ Salvia macrosiphon Boiss seed extract. Reprinted from ref. 81 with permission () 2020 Elsevier B.V.

temperature difference, $\Delta T$, between the temperature of sample and reference material. Modern and automatic thermal analysis equipment makes it possible to carry out simultaneous TGA and DTA measurements. Fig. 9 shows the TGA and DTG diagram of the nanoceria prepared from Saliva macrosiphon Boiss seeds (SmB) extract which is a capping agent. TG/DTG analysis was used to evaluate thermal behavior of nanoceria. The peak centered at $145{ }^{\circ} \mathrm{C}$ in the DTG curve confirmed the first $34 \%$ weight loss, and is related to the reduced water absorption on the surface and pore nanoceria. TGA curve peak centered at $230{ }^{\circ} \mathrm{C}$ in DTG curve was related to the $30 \%$ weight loss between 200 and $400{ }^{\circ} \mathrm{C}$, and decomposition of the organic compound of $\mathrm{SmB}$ seeds extract. $64 \%$ of total weight loss up to $400{ }^{\circ} \mathrm{C}$, and there was no thermal feature was observed above $400{ }^{\circ} \mathrm{C}$ which confirmed its thermal stability up to $1000{ }^{\circ} \mathrm{C} .{ }^{86}$

\section{Applications of nanoceria in electrochemical sensors}

Nanoceria is widely used in electrochemical sensing with better reactivity due to their crystal structure with multiple oxygen vacancy defects, and high ionic conductivity characteristics. Unique characteristics of ceria and nanoceria, e.g., catalytic activity, enzyme mimetic properties, ability to transfer oxygen, switchable redox reactivity, surface coating, and surface reactivity, allow their use in electrochemical sensors. Their high isoelectric point, adsorption capacity, mechanical strength, non-toxicity, and good biocompatibility, enable them to adapt to the requirements for sensors employed with biological matrices. ${ }^{87}$ Nanoceria is an ideal material to immobilize negatively charged biomolecules, due to its isoelectric point, e.g., 9.2.
These nanoparticles can carry our different functions in sensors, e.g., transduction element, amplifier to enhance chemical and electrochemical signals, catalyst and nanozyme that can replace biological enzymes, and label in bio-affinity assays. ${ }^{\mathbf{8 8 , 8 9}}$ Electrochemical behavior of ceria and nanoceria depend on their morphologies affected by the growth rates of ceria nanocrystalline relied on solvent composition. Furthermore, shifting between oxidation states of $\mathrm{Ce}^{3+}$ and $\mathrm{Ce}^{4+}$ enhances electrochemical property of nanoceria.

\subsection{Electrochemical sensor}

Electrochemical sensors consist of two basic components, e.g., a chemical recognition system and a physical transducer. Physical transducers are electrodes that convert recognition system to a measured electroanalytical signal. The use of nanoparticles in electrodes one strategy to increase sensitivity, to enhance stability, and to improve performance of electrochemical methods. In most cases, the presence of ceria increase the surface area, i.e., more nanoparticles could attach to the surface which enhances the direct electron transfer rate. ${ }^{89}$ For example in one study using nanoceria, a non-enzymatic sensor for monitoring glucose was developed. The combination of nanoceria and gold nanoparticles (AuNPs) on glassy carbon electrodes (GCE) enhanced the enzyme-electron transfer, and increased the electron transfer rate. Surface of GCE was modified by dropping and drying dispersion of $\mathrm{CeO}_{2}$, followed by addition of chitosan to fix $\mathrm{CeO}_{2}$ nano crystalline. $\mathrm{CeO}_{2}$ modified electrodes were subsequently immersed in tetra chloroauric acid $\left(\mathrm{HAuCl}_{4}\right)$ solution. Then, the constant potential was applied over the time to deposit AuNPs to the electrode surfaces. Detection limit was found as $2.86 \times 10^{-3} \mathrm{mM}$ with a linear 
A

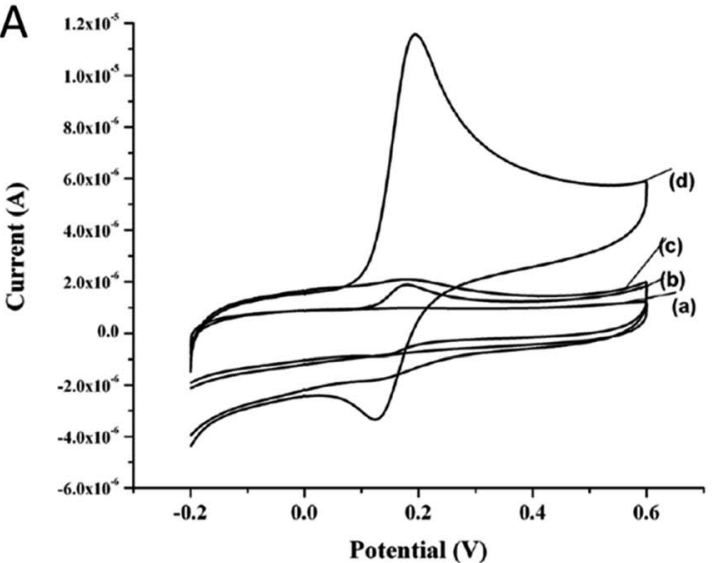

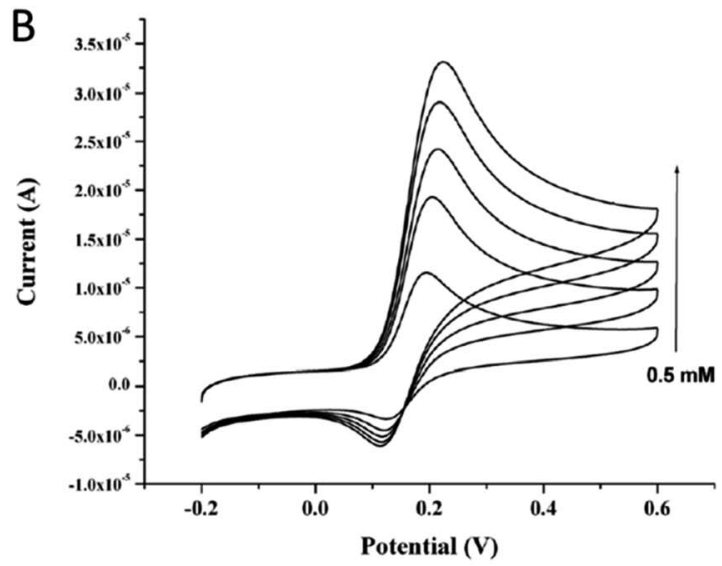

Fig. 10 (A) Cyclic voltammograms of (a) bare CPE, (b) CPE + dopamine, (c) CPE/nanoceria, and (d) CPE/nanoceria + dopamine. (B) Cyclic voltammograms of $\mathrm{CPE} /$ nanoceria modified electrodes with various concentration of dopamine from 0.5 to $0.25 \mathrm{mM}$. Reprinted from ref. 88 with permission @ 2020 Springer Nature Switzerland AG.

range between 0.02 and $0.6 \mathrm{mM}$. The sensor also showed good stability, reproducibility, and selectivity. ${ }^{90} \mathrm{C} / \mathrm{CeO}_{2}$ composites also showed an excellent performance as an electrochemical glucose sensor. Composites were attached to GCE surface using chitosan (C). $\mathrm{C} / \mathrm{CeO}_{2}$ coated electrodes detected glucose in the range between $2.0 \mu \mathrm{M}$ and $1.8 \mathrm{mM}$ with a detection limit of 0.8 $\mu \mathrm{M} .{ }^{91}$

Carbon paste electrode (CPE) modified with $\mathrm{CeO}_{2}$ nanorods embedded in nickel hydroxide $\left(\mathrm{Ni}(\mathrm{OH})_{2}\right)$ matrix was used for non-enzymatic glucose detection. Electrochemical response of $\mathrm{CeO}_{2} / \mathrm{Ni}(\mathrm{OH})_{2}$ nanocomposite was significantly improved due to the synergetic effect between $\mathrm{CeO}_{2}$ and $\mathrm{Ni}(\mathrm{OH})_{2}$. LOD was found as $1.13 \mu \mathrm{M}$, and response time was less than $5 \mathrm{~s} .{ }^{92}$ The affinity of $\mathrm{CeO}_{2}$ towards $\mathrm{H}_{2} \mathrm{O}_{2}$. Using this method, direct measurement of $\mathrm{H}_{2} \mathrm{O}_{2}$ could be used to detect, quantify, and diagnose pathological conditions, e.g., infection and inflammation. ${ }^{89}$ Modified GCE via nanohybrid of single-walled carbon nanohorns (SWCNHs) enveloped with $\mathrm{CeO}_{2}$ in a coreshell hierarchy was successfully applied as an electrochemical sensor. Ink-like suspensions of SWCNHs@ $\mathrm{CeO}_{2}$ were cast on the clean GCE surface, and dried in the oven. Electro-reduction of $\mathrm{H}_{2} \mathrm{O}_{2}$ was catalyzed with the fast transition between $\mathrm{Ce}^{3+}$ and $\mathrm{Ce}^{4+}$ that changed the number of oxygen vacancies due to the synergetic effect of $\mathrm{CeO}_{2}$ layer and the nanocarbon. The constructed biosensor was selective, robust, and anti-interference of some materials. ${ }^{\mathbf{9 2}}$ Electrochemical sensors based on nanoceria for the detection of dopamine (DA) molecules were also reported. Therefore, the detection of dopamine with high sensitivity is quite essential. Fig. $10 \mathrm{~A}$ presents the cyclic voltammograms of bare and nanoceria modified CPE in the presence or absence of DA. Bare CPE showed a small DA oxidation peak at $+0.2 \mathrm{~V}$ (Fig. $10 \mathrm{~A}(\mathrm{a})$ ). On the other hand, nanoceria
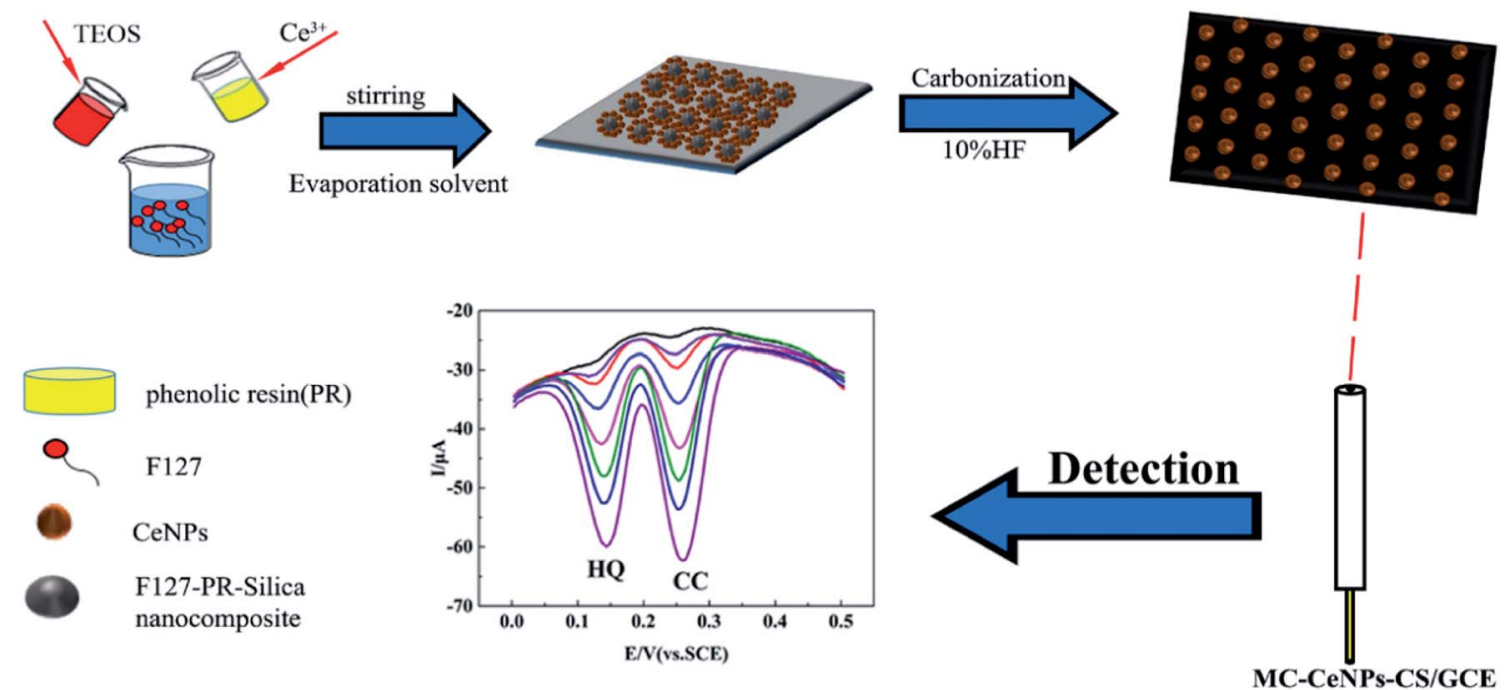

Fig. 11 Scheme of the fabrication of mesoporous carbon and ceria nanoparticles composite (MC-CeNPs), and the simultaneous detection of hydroquinone (HQ) and catechol (CC). Reprinted from ref. 93 with permission @ 2019 MDPI, Basel, Switzerland. 
modified CPE showed a well-defined and strong oxidation peak at $+0.2 \mathrm{~V}$, and a reduction peak around $+0.13 \mathrm{~V}$ (Fig. 10A(c)). Increasing DA concentration resulted in an increase in the anodic peak current as shown in Fig. 10B. This data confirmed that the surface confined species resulted in a redox peak current. $^{93}$

Nanoceria can neutralize free radical chemical species by undergoing redox changes $\left(\mathrm{Ce}^{3+} \leftrightarrow \mathrm{Ce}^{4+}\right)$. Based on this characteristic, cyclic voltammetry (CV) and chronoamperometry responses of multi-valent nanoceria on the GCE in presence of $\mathrm{H}_{2} \mathrm{O}_{2}$ was developed as an enzyme-free nanoceria-based sensor. This electrochemical sensor detected ultra-low concentration of analyte, e.g., limit of quantitation is $0.1 \mathrm{pM}$ of $\mathrm{H}_{2} \mathrm{O}_{2} \cdot{ }^{94}$ Michaelis-Menten mechanism of catalase-like activity of ceria film on GCE electrode was developed for $\mathrm{H}_{2} \mathrm{O}_{2}$ detection below $5 \mu \mathrm{M}$ detection limit without using a mediator. ${ }^{95}$ In a recent study, multi walled carbon nanotubes (MWCNTs) with nanoceria and poly-3,4-ethylenedioxythiophene

(MWCNTs/CeO 2 -PEDOT) modified GCE was used for their electrocatalytic effects toward dopamine. Under optimum conditions, two wide linear ranges, 0.1-10 $\mu \mathrm{mol} \mathrm{L} \mathrm{L}^{-1}$ and $40-400 \mu \mathrm{mol} \mathrm{\textrm {L } ^ { - 1 }}$ with a low limit of detection, e.g., $0.03 \mu \mathrm{mol} \mathrm{L}{ }^{-1}$ was obtained. Interferences were not observed for the designed sensor. ${ }^{96}$ Detections of DA, ascorbic acid, uric acid, and acetaminophen were studied using $\mathrm{CeO}_{2}$-carbon nanotubes (CNTs) modified GCEs. The existence of nanoceria on CNT surface increased the surface area and electron transfer between neuro-transmitters and electrodes. Electrochemical behavior of electrodes was determined with differential pulse voltammetry (DPV), electrochemical impedance spectroscopy (EIS), and CV. A linear behavior was determined for DA, ascorbic acid, uric acid, and acetaminophen have been ranged 0.01-900 $\mu \mathrm{M}, 0.01-700 \mu \mathrm{M}, 0.01-900 \mu \mathrm{M}$, and 0.01$900 \mu \mathrm{M}$ with detection limits of $3.1 \mathrm{nM}, 2.6 \mathrm{nM}, 2.4 \mathrm{nM}$ and
$4.4 \mathrm{nM}$, respectively. ${ }^{97} \mathrm{~A}$ mesoporous carbon and nanoceria composites (MC-CeNPs) modified GCEs were developed to detect hydroquinone (HQ) and catechol (CC) with high sensitivity and selectivity. Attaching (MC-CeNPs) onto electrodes resulted in fast electron transfer ability. Fig. 11 shows the schematic of the preparation of MC-CeNPs modified electrodes. ${ }^{98}$ Screen printed carbon electrode (SPCE) modified with polyacrylic acid coated nanoceria (PAA-CNPs) was developed based on $\mathrm{Fe}(\mathrm{CN})_{6}{ }^{3-/ 4-}$ redox system. Deposition of PAA-CNPs into SPCE was carried out by applying a potential. Here, the presence of PAA-CNPs on the electrode surface exerted a high oxidative effect on $\mathrm{Fe}(\mathrm{CN})_{6}{ }^{4-} .{ }^{99}$ The gold electrode (GE) modified with ceria microfluidic sensor was also developed for the detection of $\mathrm{H}_{2} \mathrm{O}_{2}$ directly secreted from living cells. $\mathrm{CeO}_{2}$ nanosheets exhibited a triple-enzyme mimetic activity (oxidase, catalase, and peroxidase-like on $\mathrm{GE}$ ), i.e., $\mathrm{H}_{2} \mathrm{O}_{2}$ in the living cell could be detected. The sensor showed a high sensitivity threshold $226.4 \mu \mathrm{A} \mathrm{cm} \mathrm{cm}^{-2} \mu \mathrm{M}^{-1}$ with a low detection limit of 20 nM. $^{100}$

$\mathrm{CeO}_{2} /$ reduced graphene oxide (rGO) nanocomposite modified GCEs have been constructed for the detection of DA and ascorbic acid. rGO was used as a matrix in the composite, increased the concentration of oxygen vacancies, coupled and exhibited the improvement of the nanocrystal conductivity and charge transfer (Murali et al. 2019). $\mathrm{CeO}_{2} / \mathrm{rGO}-\mathrm{GCE}$ showed a good performance and selectivity for the detection of organophosphorus pesticide fenitrothion, even in the presence of interferences in water samples. ${ }^{\mathbf{1 0 1}} \mathrm{CeO}_{2}$ /graphene oxide (GO) composite-based electrochemical sensor was developed for the detection of toxic methyl orange as a dye. GCE was modified with GO-polylactic acid (PLA)- $\mathrm{CeO}_{2}$, and the electrochemical characterization of GO-PLA- $\mathrm{CeO}_{2}$ composite exhibited a very advantageous behavior for dye removal. ${ }^{102}$ GCE modified with

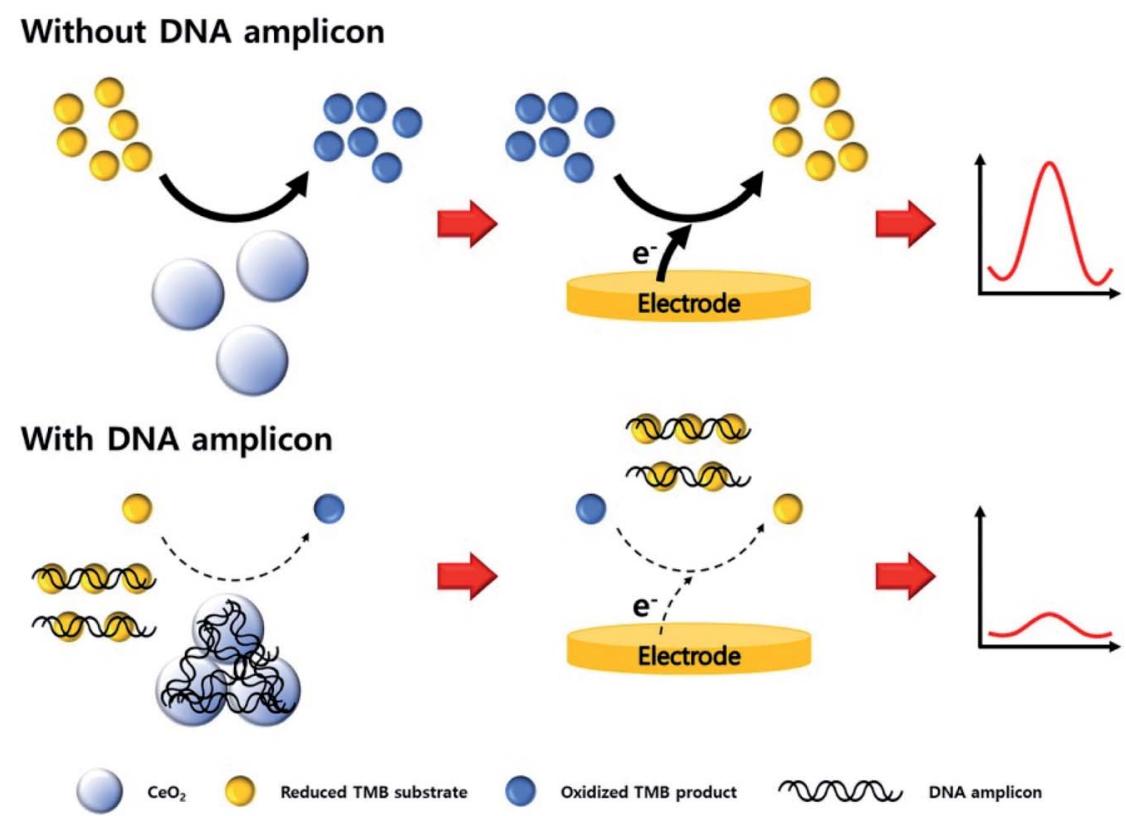

Fig. 12 Schematic illustration of the DNA detection with an electrochemical method based on oxidase-mimicking activity of $\mathrm{CeO}_{2}$. Reprinted from ref. 107 with permission (c) 2020 Elsevier B.V. 
organic-inorganic nil-blue- $\mathrm{CeO}_{2}$ nanohybrid was developed for the detection of hydrazine. ${ }^{\mathbf{1 0 3}} \mathrm{A}$ nanostructured copper-ceria $\left(\mathrm{CuO}-\mathrm{CeO}_{2}\right)$ composite prepared by calcination of $\mathrm{Cu}(\mathrm{II}) / \mathrm{Ce}(\mathrm{III})$ metal organic framework was developed for the detection of insecticide malathion. ${ }^{104}$ An amperometric sensor which contained $\mathrm{CeO}_{2}-\mathrm{CuO}$ modified GCEs was designed for nitrite detection. ${ }^{105}$ Nanoceria as nanocomposite with $\mathrm{Cu}_{2} \mathrm{O}$ and platinum was introduced for a sensitive electro-oxidation and selectivity capacity toward the detection of DA and paracetamol. $\mathrm{Pt} / \mathrm{CeO}_{2} @ \mathrm{Cu}_{2} \mathrm{O}$ modified $\mathrm{CPE}$ exhibited a linear behavior for DA and paracetamol with the detection limits, e.g., $0.079 \mu \mathrm{M}$ and $0.091 \mu \mathrm{M}$, over the range between 0.5 and $100 \mu \mathrm{M} \cdot{ }^{106}$ The stannum doped CeNPs modified glassy carbon paste electrode was used for the detection of an anti-cancer drug, e.g., dacarbazine.$^{107}$ In this work, ruthenium-loaded $\mathrm{CeO}_{2}$ nanocubes $(\mathrm{Ru} /$ $\mathrm{CeO}_{2}$ ) with rich oxygen vacancies were used to construct an electrochemical sensing interface. The designed nanocomposite electrode enhanced the electrochemical signals, and enabled the detection of $\mathrm{Hg}$ (II) ion. ${ }^{108} \mathrm{Fe}_{3} \mathrm{O}_{4} / \mathrm{CeO}_{2} @ A u$ modified
GCEs was developed for microRNA-21 detection, and exhibited good repeatability, stability, reproducibility, and antiinterference ability. ${ }^{109}$

Modifications on the screen printed electrodes (SPEs) with nanoceria was developed. A colloidal nanoceria was dropped onto SPEs. SPEs/CeNPs was used in the detection of total antioxidant capacity, e.g., caffeic acid, gallic acid, quercetin, ascorbic acid, trans resveratrol, and dimethyl sulfoxide in wine samples. ${ }^{110}$ Electrochemical sensor for the detection of oxymetazoline hydrochloride was developed by modifying SPEs with nanoceria. The developed sensor used paraffin oil (pasting liquid) and nanoceria (conductor) to increase electrical conductivity of electrode surface area. An ion pairing agent, e.g., tetraphenyl borate, was incorporated with the sensor as a sensing membrane of the drug material. SPEs/CeNPs sensor displayed a good performance, significant linear response, and stable reproducible potential for five months. ${ }^{\mathbf{1 1 1}} \mathrm{GE}$ was modified with nanoceria, and showed oxidase-mimicking activity with $3,3^{\prime}, 5,5^{\prime}$-tetramethylbenzidine (TMB) substrate. Oxidase-

Table 1 Application of nanoceria in electrochemical sensing in the last four years (2017-2020). Abbreviations: LoD: limit of detection, LR: linear range, S: sensitivity

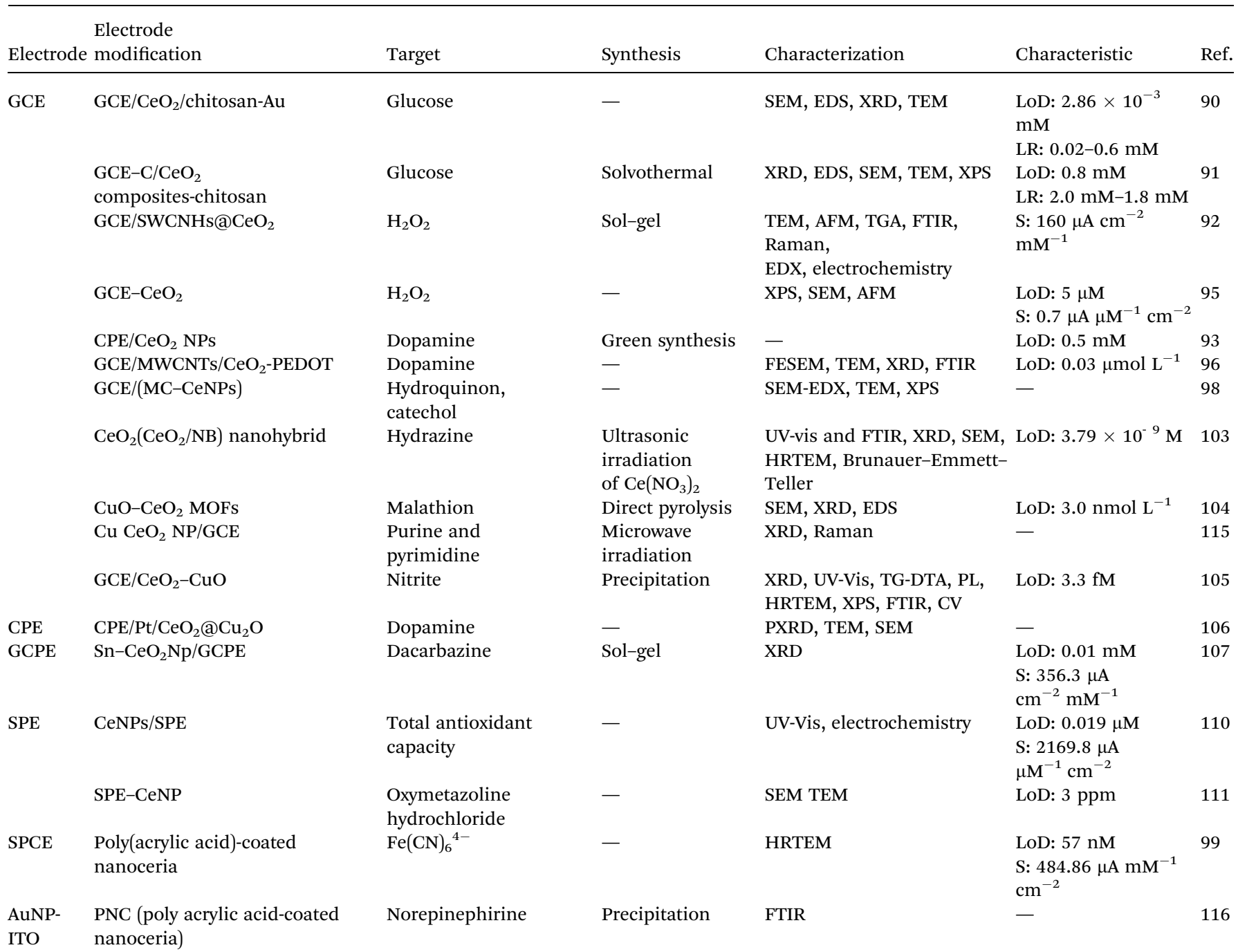


Table 2 Nanoceria-based electrochemical biosensors introduced in the last four years (2017-2020)

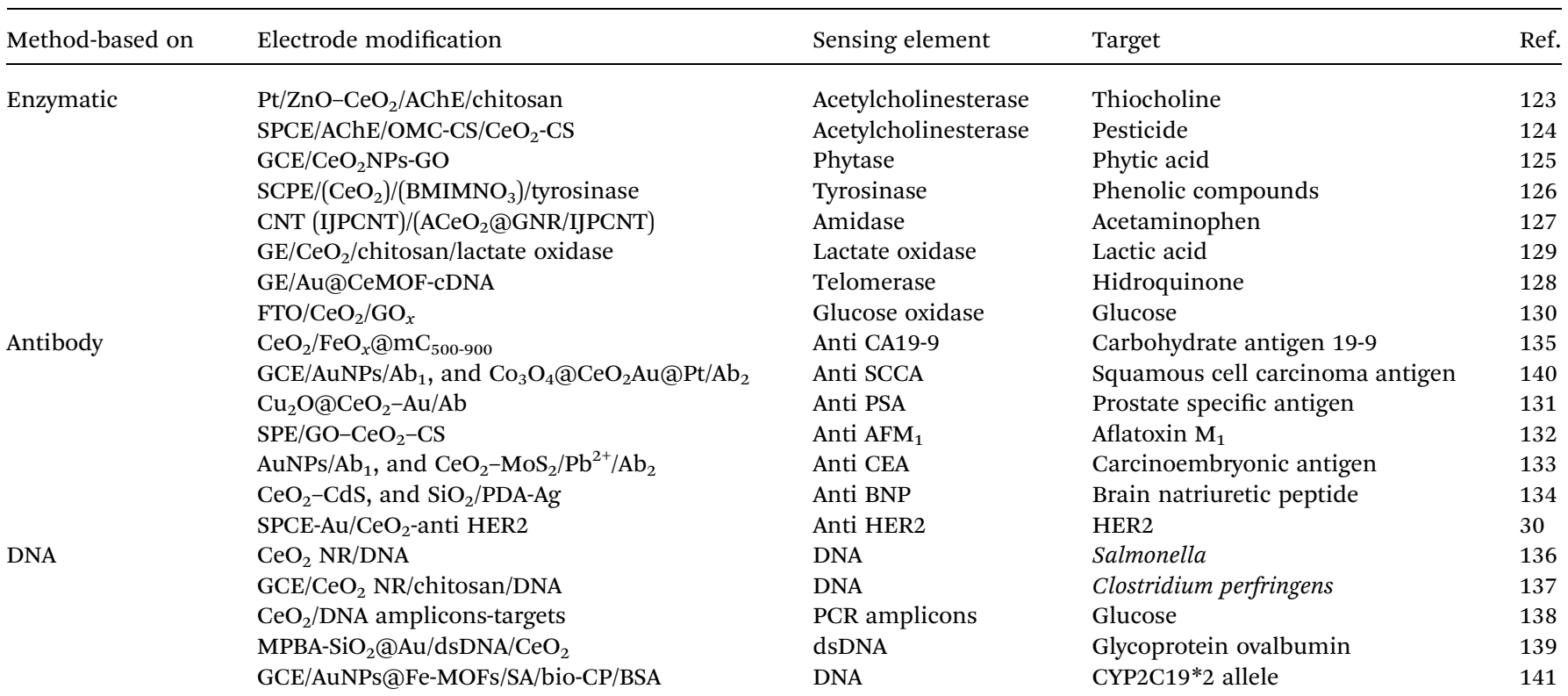

like reaction of nanoceria-TMB complex could carry a DNA amplicon that changes the electrochemical signal. The proposed sensor exhibited a rapid determination of E. coli DNA amplicon without the need for a post-purification. Fig. 12 shows the schematic illustration of the electrochemical DNA detection based on oxidase-mimicking of nanoceria. ${ }^{112}$

Another nanoceria based electrochemical sensor for $\mathrm{H}_{2} \mathrm{O}_{2}$ detection was developed based on the formation of nanocomposite gold nanoparticles-graphene sheets@cerium oxide (GS@CeO ${ }_{2}$ ) modified GE. GElGS@CeO ${ }_{2} / \mathrm{Au}$ showed a good performance towards the electrocatalytic reduction of $\mathrm{H}_{2} \mathrm{O}_{2}$, and achieved a low limit of detection of $2.6 \times 10^{-4} \mathrm{mM}^{113}$ The screen printed nanostructured cerium oxide was applied on prefabricated GE for the indirect detection of melamine in the presence of ascorbic acid. A wide linear melamine concentration range between $0.01 \mathrm{ppb}$ and $10 \mathrm{ppm}$, and the limit of detection without and with ascorbic acid, e.g., $1.5 \times 10^{-3}$ and $2.4 \times 10^{-3} \mathrm{ppb}$, respectively were obtained by using this electrode. ${ }^{114}$ The use of nanoceria with different electrode types, and modification techniques for various analytes introduced in the last four years were summarized in Table 1.

\subsection{Electrochemical biosensors}

Biosensors are analytical devices that utilize biochemical reactions to detect target analytes. Biosensors contains biochemical compounds that recognize the targeted analytes. In order to improve the performance of biosensors, various nanomaterials, e.g., carbon nanotubes, graphene nanosheets, metal nanoparticles, metal oxide nanoparticles, and their nanoconjugates were incorporated within the biosensors. ${ }^{117-121}$ Metal nanoparticles and metal oxides have been widely used in biosensors to amplify signals and increase surface area, as well as employed as stabilizers for biological receptors. ${ }^{122}$
Electrochemical behavior of nanoceria towards the oxidation and reduction of $\mathrm{H}_{2} \mathrm{O}_{2}$ results in a highly sensitive $\mathrm{H}_{2} \mathrm{O}_{2}$ detection. Table 2 shows the applications employing nanoceria in biosensing in the last four years (2017-2020).

4.2.1 Enzyme-based electrochemical biosensor. A Pt/ZnO$\mathrm{CeO}_{2} / \mathrm{AChE} /$ chitosan based biosensor was developed for sensitive quantification of thiocholine with acetylcholinesterase (AChE) enzyme. AChE interacts with substrate of acetylthiocholine chloride (ATCl) and produces an electroactive product that leads a clear oxidation peak. In order to prepare $\mathrm{ZnO}-\mathrm{CeO}_{2} /$ $\mathrm{AChE} /$ chitosan nanocomposite, different percentages of $\mathrm{ZnO}$, $\mathrm{CeO}_{2}$, and chitosan were dispersed in AChE coated onto Pt electrode's surface. The biosensor showed high electron transfer rate, biocompatibility, and good conductivity. ${ }^{123}$ An AChE enzyme biosensor was developed for the detection of organophosphorus pesticide residue using cerium oxide-chitosan $\left(\mathrm{CeO}_{2}-\mathrm{CS}\right)$ modified SPCEs and mesoporous carbon-chitosan (OMC-CS). $\mathrm{CeO}_{2}-\mathrm{CS}$ was dropped on the SPCE surface, and $\mathrm{CeO}_{2}-\mathrm{CS} / \mathrm{SPCE}$ was modified with OMC-CS. Finally, AChE was immobilized onto SPCE to obtain AChE/OMC-CS/CeO ${ }_{2}-\mathrm{CS} /$ SPCE. The proposed AChE biosensor exhibited a good reproducibility and high stability. ${ }^{124}$ The phytase enzyme immobilization on a chemically modified cerium oxide nanoparticles decorated graphene oxide $\left(\mathrm{CeO}_{2} \mathrm{NPs}-\mathrm{GO}\right)$ on the surface of GCE was used for the detection of phytic acid (PA). The decrease in the current for the ferricyanide cyanide solution with PA concentration on the $\mathrm{CeO}_{2}$ NPsGO electrode surface was elucidated in the range between 0.066 and $6.6 \mathrm{ppb}$. The developed PA biosensor provided a much lower detection limit $(\mathrm{LOD}=0.001$ $\mathrm{ppb}$ ) compared to previously reported electrochemical techniques for PA detection. ${ }^{125}$

Tyrosinase modified cerium oxide $\left(\mathrm{CeO}_{2}\right) / 1$-butyl-3methylimidazolium nitrate composite was deposited on SPCE for the detection of phenolic compounds. In this technology, 


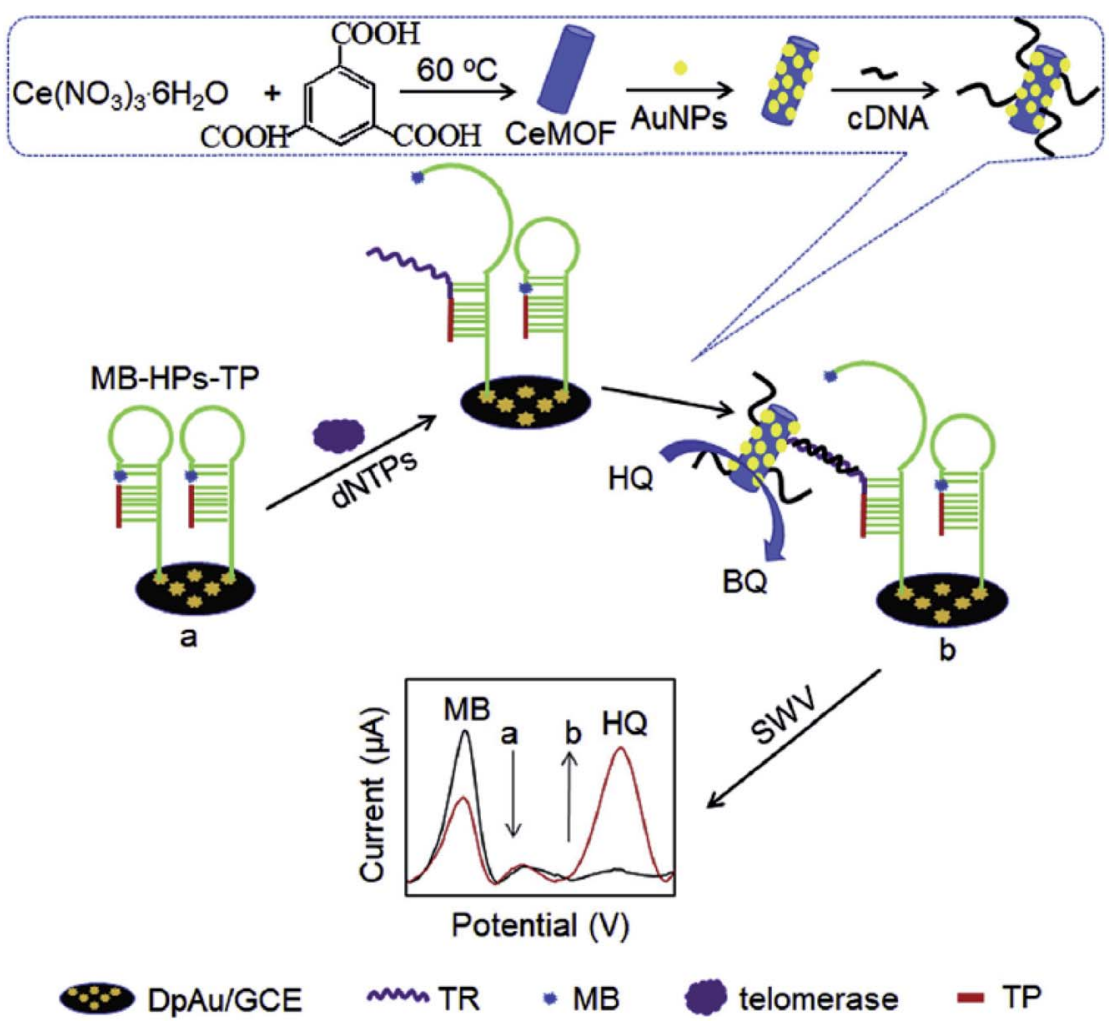

Fig. 13 Experimental steps of the detection of telomerase activity based on catalysis of AuCCeMOF toward HQ oxidation and conformation switch of MB-labeled hairpin DNA. Reprinted from ref. 123 with permission (c) 2020 Elsevier B.V.

$\mathrm{BMIMNO}_{3}$ was used to enhance electron transfer of medium to the electrode surface and the conductivity of the electrodes. The developed biosensor possesses an LOD and sensitivity, e.g., $0.1221 \mu \mathrm{M}$ and $80.86 \mathrm{nA} \mu \mathrm{M}^{-1}$, respectively. ${ }^{126}$ An amidase/ cerium dioxide@graphene nanoribbon composite modified inkjet-printed carbon nanotube electrode ( $\mathrm{ACeO}_{2} @ G N R /$ IJPCNT) was constructed for the detection of acetaminophen. IJPCNT electrodes had small sample volume, e.g., $5 \mu \mathrm{L}$, corporates amidase A enzyme that showed a high selectivity and sensitivity. The proposed biosensor resulted in a broad linear range of concentration between 1 and $100 \mu \mathrm{M}$, and a low limit of detection of $0.18 \mu \mathrm{M}$ of acetaminophen. ${ }^{\mathbf{1 2 7}}$ A ratiometric electrochemical biosensor based on gold nanoparticles functionalized with cerium-based metal-organic frameworks tagged cDNA (Au@CeMOF-cDNA) have been developed for telomerase activity. CeMOFs was formed by a green method synthesized of cerium nodes), where 1,3,5-benzenetricarboxylic acid was used as a linker. Initially, methylene blue (MB) modified hairpin DNA probe and telomerase primer (TP) immobilized on the glassy carbon-deposited gold electrodes (GCE-DpAu) via Au-S attachment. In the presence of telomerase and dNPs, the extended TP could open DNA hairpin, and keep the MB away from the electrode surface, which results in a decrease in the electrochemical signal. Meanwhile Au@CeMOF-cDNA was captured by DNA probe via hybridization, and leading to an increase in electrochemical signal due to its electrocatalytic behavior toward hydroquinone (HQ) oxidation. The experimental steps is shown in Fig. 13. The proposed biosensor showed a wide range of telomerase activity between $2 \times 10^{2}$ and $2 \times 10^{6}$ cells per $\mathrm{mL}$ with a detection limit of 27 cells per $\mathrm{mL} .^{128}$

A higher catalytic of nanoceria embedded in amorphous carbon and associated with chitosan-lactate oxidase was offered to employ it as a lactic acid biosensor. Oxidation of lactic acid by lactate oxidase produced by $\mathrm{H}_{2} \mathrm{O}_{2}$ was measured with $\mathrm{CV}$ on the gold electrode. The sensor showed a wide linear range from 3 to $300 \mu \mathrm{M}$ with a low detection limit of $300 \mathrm{nM}$ lactic acid. ${ }^{129}$ Cerium oxide based on $\mathrm{GO}_{x}$ enzyme that immobilizes through electrostatic interaction on the fluorine doped tin oxide (FTO) electrode modified $\mathrm{CeO}_{2}$ nanostructures. The developed biosensors showed a sensitivity between 208 and $2290 \mu \mathrm{A} \mathrm{cm}^{-2}$ $\mathrm{mM}^{-1}$, with a detection limit of $1 \mathrm{nM}$. Increased surface area and high defect concentration on the surface enhance performance of the proposed biosensor. ${ }^{130}$

4.2.2 Electrochemical immunosensors. Antibody-based electrochemical biosensors, in other words, immunosensors use antibodies as capturing agents. Immunosensors possess high sensitivity thanks to numerous nanomaterials that facilitate electron transfer rate and carrying capacity. ${ }^{129}$ For example, bimetallic cerium and ferric oxide nanoparticles embedded in mesoporous carbon matrix $\left(\mathrm{CeO}_{2} / \mathrm{FeO}_{x} @ m \mathrm{~m}\right)$ was employed for the detection of carbohydrate antigen 19-9 (CA19-9) with EIS. Calcination at different temperatures within highly graphitized mesoporous carbon matrix was performed to obtain bimetallic Ce-Fe-based metal organic framework (CeFe-MOF). CA 19-9 antibody was anchored to $\mathrm{CeO}_{2} / \mathrm{FeO}_{x} @ m \mathrm{~m}$ network via esterlike bridging between carboxylic groups of antibody. LOD was 
found as $10 \mu \mathrm{U} \mathrm{mL}^{-1}$ within a broad range, e.g., from $0.1 \mathrm{mU}$ $\mathrm{mL}^{-1}$ to $10 \mathrm{U} \mathrm{mL}^{-1} .^{129}$ A core-shell nanocomposite amino functionalized cuprous oxide@ceric dioxide $\left(\mathrm{Cu}_{2} \mathrm{O} @ \mathrm{CeO}_{2}-\right.$ $\mathrm{NH}_{2}$ ) was introduced for the detection of prostate specific antigen (PSA). Such substrate possess btter electrocatalytic activity via the reduction of $\mathrm{H}_{2} \mathrm{O}_{2}$ and the developed $\mathrm{Cu}_{2}$ $\mathrm{O} @ \mathrm{CeO}_{2}-\mathrm{Au}$ based immunosensor provided a low detection limit, e.g., $0.03 \mathrm{pg} \mathrm{mL}{ }^{-1}$ PSA. $^{131}$

SPEs modified with graphene oxide-chitosan (GO-CS) and cerium oxide-chitosan $\left(\mathrm{CeO}_{2}-\mathrm{CS}\right)$ were designed for the detection of aflatoxin M1 (AFM1). The synergic effects of GO, nanoceria, and chitosan resulted in strong electrical conductivity, good redox property, and strong complexation. Furthermore, it accelerated electron transfer, and allowed larger numbers of anti-AFM1 antibody (ab-AFM1) immobilization. DPV and CV characterization tests showed a detection limit, e.g., $0.009 \mu \mathrm{g} \mathrm{L}{ }^{-1}$ AFM1. ${ }^{132}$ A nanohybrid of molybdenum disulphide with cerium oxide $\left(\mathrm{CeO}_{2}-\mathrm{MoS}_{2}\right)$ was developed to absorb lead ions $\left(\mathrm{Pb}^{2+}\right)$, attaching to an capturing antibody $\left(A b_{2}\right)$ for the detection of carcinoembryonic antigen (CEA). Square wave voltammetry measurements employing the $\mathrm{Pb}^{2+}$ electrical signal demonstrated a limit of detection, e.g., $0.3 \mathrm{pg}$ $\mathrm{mL}^{-1}$ of CEA. ${ }^{133}$ A sandwich type photoelectrochemical (PEC) immunosensor was developed for the detection of brain natriuretic peptide (BNP). The photoactive $\mathrm{CeO}_{2}-\mathrm{CdS}$ platform employs $\mathrm{SiO}_{2} / \mathrm{PDA}-\mathrm{Ag}$ nanocomposites for signal amplification. Using $\mathrm{CeO}_{2}-\mathrm{CdS}$ further enhanced photocurrent responses thanks to the well matched energy band. In order to improve the sensitivity of the immunosensor, Ag nanoparticles (AgNPs) were used due to their ability to anchor antibodies via the chemical bonding between AgNPs and $-\mathrm{NH}_{2}$ of antibodies. This PEC immunosensor exhibited a low detection limit, e.g., $0.05 \mathrm{pg} \mathrm{mL}^{-1}$ within a range between

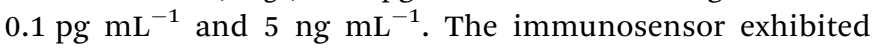
good stability, reproducibility and specificity, which could be applicable for the detection of different biomarkers. ${ }^{134}$ AuNP decorated $\mathrm{CeO}_{2}-\mathrm{CuO}$ corporated with $\mathrm{Au} @ A g$-thionine (signal label) was constructed for the detection of procalcitonin (PCT). The proposed sandwich immunosensor provided a detection limit of $0.17 \mathrm{pg} \mathrm{mL}^{-1}$ PCT within a linear range between $0.5 \mathrm{pg}$ $\mathrm{mL}^{-1}$ and $50 \mathrm{ng} \mathrm{mL}^{-1}$ with. ${ }^{135}$

4.2.3 DNA-based electrochemical biosensor. $\mathrm{A} \mathrm{CeO}_{2} \mathrm{NR}$ was developed to detect Salmonella pathogen. Impedimetric measurements exhibited a linear range of target DNA concentration, e.g., between $0.01 \mu \mathrm{M}$ and $2 \mu \mathrm{M}$, with a limit of detection and sensitivity, $0.01 \mu \mathrm{M}$ and $3362.1 \Omega \mu \mathrm{M}^{-1} \mathrm{~cm}^{-2}$, respectively. ${ }^{\mathbf{1 3 6}} \mathrm{CeO}_{2} \mathrm{NR}$ also exhibited a strong adsorption to DNA, and was employed as an electrochemical biosensor for the detection of Clostridium perfringens. The DNA probe immobilized on the $\mathrm{CeO}_{2} \mathrm{NR} /$ chitosan modified GCE via metal coordination bonding. Impedimetric tests showed a limit of detection $7.06 \times 10^{-15} \mathrm{~mol} \mathrm{~L}^{-1}$ of target DNA in a linear range between $10^{-14}$ and $10^{-7} \mathrm{~mol} \mathrm{~L}^{-1} \cdot{ }^{137}$ Electrostatic interaction between nanoceria and DNA was employed in a personal glucose meter (PGM) based on glucose oxidase-like activity that enabled correlation of DNA amplicon with glucose level. The biosensor is based on inducing aggregation of DNA amplicon, target DNA, and nanoceria that reduces the efficiency of nanoceria-catalyzed glucose oxidation reaction. PGM measured the level of nanoceria-suppressed conversion of glucose to gluconic acid. The proposed biosensor provided high selectivity and sensitivity. ${ }^{138}$ 4-mercaptophenylboronic acid (MPBA) molecularly imprinted polymer that is modified with $\mathrm{CeO}_{2}$ and $\mathrm{SiO}_{2}$ @Au nanocomposites were developed as a signal tag in DNA-based electrochemical biosensor for the detection of glycoprotein ovalbumin (OVA). A nicked doublestrand DNA was added to form $\mathrm{SiO}_{2} @ \mathrm{Au} / \mathrm{dsDNA} / \mathrm{CeO}_{2}$, and immobilized on the electrode surfaces. Using the developed biosensor, a broad linear range, e.g., between $1 \mathrm{pg} \mathrm{mL}^{-1}$ and $1000 \mathrm{ng} \mathrm{mL}{ }^{-1}$, and a low detection limit, $0.87 \mathrm{pg} \mathrm{mL}^{-1}$ OVA were obtained. ${ }^{139}$

\section{Conclusion}

Nanoceria can be synthesized with various physical and chemical methods including precipitation, hydrothermal, and combustion, and bio- or green synthesis methods. Nanoceria morphologies including size, shape, and distribution can spectroscopically characterized, e.g., UV-VIS, FTIR, Raman spectroscopy, photoluminescence, microscopically characterized, e.g., SEM, FESEM, TEM, HERTEM, X-ray techniques, e.g., XRD, XPS, and thermal stability tests, e.g., TGA, DTA/DTG. Among the metal oxide-based nanoparticles, nanoceria or cerium oxide nanoparticles attracted significant attention that can be used as an electrochemical sensor thanks to their high mechanical strength, oxygen ion conductivity, oxygen storage capacity, high chemical stability, and non-toxicity. Their structure exhibit strong oxygen storage capacity due to the high numbers of oxygen vacancy defects in their crystal structure. Nanoceria can also act as oxidizing and reducing agents due to the oxidation state of cerium oxide nanoparticles that can vary between +3 and +4 . Nanoceria is widely used in biosensing, e.g., acting as catalysts to mimic activity of enzymes in biosensors. Furthermore, the combination of nanoceria with different nanomaterials was realized to improve sensor performance. Vast numbers of nanomaterials were employed in electrochemical sensing with various electrodes and analytes. Biocompatibility of nanoceria helps immobilizing biomolecules with low iso-electric points through electrostatic interactions. Nanoceria also enhances sensitivity derived from various signal strengthening strategies.

\section{Conflicts of interest}

The authors declare that there is no conflict of interests regarding the publication of this paper.

\section{Acknowledgements}

This review is supported by Universitas Padjadjaran Hibah Artikel Review Scheme no. 1733/UN6.3.1/LT/2020, and Academic Leadership Grant no. 1427/UN6.3.1/LT/2020. 


\section{References}

1 J. T. Dahle and Y. Arai, Int. J. Environ. Res. Public Health, 2015, 12, 1253-1278.

2 F. Charbgoo, M. Ramezani and M. Darroudi, Biosens. Bioelectron., 2017, 96, 33-43.

3 R. Chetty and M. Singh, Int. J. Biol. Macromol., 2020, 156, 1022-1044.

4 S. A. Abid, A. A. Taha, R. A. Ismail and M. H. Mohsin, Environ. Sci. Pollut. Res. Int., 2020, 27, 30479-30489.

5 Z. Wang, X. Shen, X. Gao and Y. Zhao, Nanoscale, 2019, 11, 13289-13299.

6 S. Del Turco, G. Ciofani, V. Cappello, P. Parlanti, M. Gemmi, C. Caselli, R. Ragusa, A. Papa, D. Battaglia, L. Sabatino, G. Basta and V. Mattoli, J. Biomed. Mater. Res., Part A, 2019, 107, 1551-1562.

7 D. F. Henning, P. Merkl, C. Yun, F. Iovino, L. Xie, E. Mouzourakis, C. Moularas, Y. Deligiannakis, B. Henriques-Normark, K. Leifer and G. A. Sotiriou, Biosens. Bioelectron., 2019, 132, 286-293.

8 J. Das, Y.-J. Choi, J. W. Han, A. M. M. T. Reza and J.-H. Kim, Sci. Rep., 2017, 7, 9513.

9 J. Das, J. W. Han, Y.-J. Choi, H. Song, S.-G. Cho, C. Park, H. G. Seo and J.-H. Kim, Sci. Rep., 2016, 6, 29197.

10 P. Luches and S. Valeri, Materials, 2015, 8, 5818-5833.

11 D. Damatov, S. M. Laga, E. A. Mader, J. Peng, R. G. Agarwal and J. M. Mayer, Inorg. Chem., 2018, 57, 14401-14408.

12 E. Casals, M. F. Gusta, J. Piella, G. Casals, W. Jimenez and V. Puntes, Front. Immunol., 2017, 8, 970.

13 F. A. Ozdemir Olgun, A. Uzer, B. D. Ozturk and R. Apak, Talanta, 2018, 182, 55-61.

14 C. J. Neal, A. Gupta, S. Barkam, S. Saraf, S. Das, H. J. Cho and S. Seal, Sci. Rep., 2017, 7, 1324.

15 Y. Zhou, S. D. Uzun, N. J. Watkins, S. Li, W. Li, A. L. Briseno, K. R. Carter and J. J. Watkins, ACS Appl. Mater. Interfaces, 2019, 11, 1821-1828.

16 F. Zhou, X. Ni, Y. Zhang and H. Zheng, J. Colloid Interface Sci., 2007, 307, 135-138.

17 N. Thakur, P. Manna and J. Das, J. Nanobiotechnol., 2019, 17, 84 .

18 B. H. Chen and B. Stephen Inbaraj, Crit. Rev. Biotechnol., 2018, 38, 1003-1024.

19 M. Rashmi, R. Padmanaban, V. Karthikeyan, V. A. L. Roy, A. I. Gopalan, G. Saianand, W. J. Kim and V. Kannan, Catalysts, 2020, 10, 34.

20 Z. Mortazavi Milani, F. Charbgoo and M. Darroudi, Ceram. Int., 2017, 43, 14572-14581.

21 A. Dhall and W. Self, Antioxidants, 2018, 7, 97.

22 F. Caputo, M. Mameli, A. Sienkiewicz, S. Licoccia, F. Stellacci, L. Ghibelli and E. Traversa, Sci. Rep., 2017, 7, 4636.

23 D. Gil, J. Rodriguez, B. Ward, A. Vertegel, V. Ivanov and V. Reukov, Bioengineering, 2017, 4, 18.

24 N. K. V. Nadimpalli, R. Bandyopadhyaya and V. Runkana, Fluid Phase Equilib., 2018, 456, 33-45.
25 I. Kitsou, E. Roussi and A. Tsetsekou, Ceram. Int., 2017, 43, 3861-3865.

26 P. M. Junais and G. Govindaraj, Mater. Res. Express, 2019, 6, 045914.

27 N. Shehata, E. Samir, S. Gaballah, A. Hamed, M. Saad and M. Salah, J. Fluoresc., 2017, 27, 767-772.

28 I. Kandas, N. Shehata, I. Hassounah, P. Sobolciak, I. Krupa and R. Lewis, J. Nanophotonics, 2018, 12, 026016.

29 A. Matin, U. Baig, M. A. Gondal, S. Akhtar and S. M. Zubair, Appl. Surf. Sci., 2018, 462, 95-104.

30 Y. W. Hartati, L. K. Letelay, S. Gaffar, S. Wyantuti and H. H. Bahti, Sensing and Bio-Sensing Research, 2020, 27, 100316.

31 A. U. Badnore, A. P. Chaudhari, J. K. Patel and A. B. Pandit, Adv. Powder Technol., 2019, 30, 1058-1066.

32 P. Stelmachowski, K. Ciura, P. Indyka and A. Kotarba, Mater. Chem. Phys., 2017, 201, 139-146.

33 S. Singh and S.-L. Lo, Environ. Sci. Pollut. Res., 2018, 25, 6532-6544.

34 T. J. Fisher, Y. Zhou, T.-S. Wu, M. Wang, Y.-L. Soo and C. L. Cheung, Nanoscale, 2019, 11, 4552-4561.

35 Y. Xue, S. R. Balmuri, A. Patel, V. Sant and S. Sant, Drug Delivery Transl. Res., 2018, 8, 357-367.

36 N. Ohtake, Y. Yamane, K. Nakagawa, M. Katoh and S. Sugiyama, J. Chem. Eng. Jpn., 2016, 49, 197-203.

37 G. Jayakumar, A. Albert Irudayaraj and A. Dhayal Raj, Opt. Quantum Electron., 2019, 51, 312.

38 R. V. Lakshmi, K. Pal, T. K. Mandal and S. T. Aruna, Bull. Mater. Sci., 2019, 42, 210.

39 M. Khairy, B. G. Mahmoud and C. E. Banks, Sens. Actuators, $B, 2018,259,142-154$.

40 Y. Liao, L. He, M. Zhao and D. Ye, J. Environ. Chem. Eng., 2017, 5, 5054-5060.

41 G. Vinothkumar, P. Arunkumar, A. Mahesh, A. Dhayalan and K. Suresh Babu, New J. Chem., 2018, 42, 18810-18823.

42 M. Anandkumar, G. Vinothkumar and K. Suresh Babu, New J. Chem., 2017, 41, 6720-6729.

43 M. Zarezadeh Mehrizi, S. Ahmadi, R. Beygi and M. Asadi, Russian Journal of Non-Ferrous Metals, 2018, 59, 111-116.

44 R. Bakkiyaraj and M. Balakrishnan, J. Adv. Phys., 2017, 6, 41-47.

45 S. Zeljković, D. Jelić, H. Maruyama and J. C. Nino, Ceram. Int., 2019, 45, 10063-10071.

46 D. V. Maslennikov, A. A. Matvienko, A. A. Sidelnikov and S. A. Chizhik, Mater. Today: Proc., 2017, 4, 11495-11499.

47 Y.-P. Lan and H. Y. Sohn, Ceram. Int., 2018, 44, 3847-3855.

48 R. Álvarez-Asencio, R. W. Corkery and A. Ahniyaz, RSC Adv., 2020, 10, 14818-14825.

49 V. Mihalache, M. Secu and J. C. Grivel, Mater. Chem. Phys., 2018, 209, 121-133.

50 J. He, L. Zhou, J. Liu, L. Yang, L. Zou, J. Xiang, S. Dong and X. Yang, Appl. Surf. Sci., 2017, 402, 469-477.

51 S. Mohajer, M. Chamsaz, E. K. Goharshadi and S. Samiee, Sep. Sci. Technol., 2017, 52, 1652-1659.

52 S. Barkam, J. Ortiz, S. Saraf, N. Eliason, R. McCormack, S. Das, A. Gupta, C. Neal, A. Petrovici, C. Hanson, 
M. D. Sevilla, A. Adhikary and S. Seal, J. Phys. Chem. C, 2017, 121, 20039-20050.

53 A. Bhalkikar, T.-S. Wu, C. M. Marin, T. J. Fisher, M. Wang, I. H. Wells, A. Sarella, Y.-L. Soo and C. L. Cheung, Nanoscale, 2018, 10, 9822-9829.

54 J.-H. Pang, Y. Liu, J. Li and X.-J. Yang, Rare Met., 2019, 38, 73-80.

55 O. S. Hammond, K. J. Edler, D. T. Bowron and L. TorrenteMurciano, Nat. Commun., 2017, 8, 14150.

56 G. Sharmila, C. Muthukumaran, H. Saraswathi, E. Sangeetha, S. Soundarya and N. M. Kumar, Ceram. Int., 2019, 45, 12382-12386.

57 B. Elahi, M. Mirzaee, M. Darroudi, K. Sadri and R. Kazemi Oskuee, Colloids Surf., B, 2019, 181, 830-836.

58 H. E. A. Mohamed, S. Afridi, A. T. Khalil, M. Ali, T. Zohra, R. Akhtar, A. Ikram, Z. K. Shinwari and M. Maaza, Nanomedicine, 2020, 15, 467-488.

59 F. Javadi, M. E. Taghavizadeh Yazdi, M. Baghani and A. Eshaghi, Mater. Res. Express, 2019, 6, 065408.

60 F. T. Thema, D. Letsholathebe and K. Mphale, Mater. Today: Proc., 2021, 36, 435-439.

61 P. S. P. Jyothi and N. J. Tharayil, AIP Conf. Proc., 2020, 2222, 020006.

62 N. Fereydouni, H. R. Sadeghnia, M. Ghayour Mobarhan, J. Movaffagh, V. Baradaran Rahimi, A. Hashemzadeh, Z. Mardani and M. Darroudi, J. Mol. Struct., 2019, 1186, 23-30.

63 P. V. Valsaraj and Divyarthana, AIP Conf. Proc., 2019, 2162, 020022.

64 A. Miri and M. Sarani, Ceram. Int., 2018, 44, 12642-12647. 65 A. Alayli Gungor, H. Nadaroglu, A. Babagil and H. Onem, Journal of Advanced Materials and Processing, 2018, 6, 12-21.

66 T. Arunachalam, M. Karpagasundaram and N. Rajarathinam, Mater. Sci., 2018, 35, 791.

67 M. B. Khorrami, H. R. Sadeghnia, A. Pasdar, M. GhayourMobarhan, B. Riahi-Zanjani and M. Darroudi, J. Mol. Struct., 2018, 1157, 127-131.

68 H. Kaygusuz and F. B. Erim, Chem. Pap., 2020, 74, 23572363.

69 E. Nourmohammadi, R. Kazemi Oskuee, L. Hasanzadeh, M. Mohajeri, A. Hashemzadeh, M. Rezayi and M. Darroudi, Ceram. Int., 2018, 44, 19570-19575.

70 C. Gunawan, M. S. Lord, E. Lovell, R. J. Wong, M. S. Jung, D. Oscar, R. Mann and R. Amal, ACS Omega, 2019, 4, 9473-9479.

71 A. A. Baqer, K. A. Matori, N. M. Al-Hada, A. H. Shaari, E. Saion and J. L. Y. Chyi, Results Phys., 2017, 7, 611-619.

72 J. Calvache-Muñoz, F. A. Prado, L. Tirado, L. C. DazaGomez, G. Cuervo-Ochoa, H. L. Calambas and J. E. Rodríguez-Páez, J. Inorg. Organomet. Polym. Mater., 2019, 29, 813-826.

73 S. S. E. Shaer, T. A. Salaheldin, N. M. Saied and S. M. AbdElazim, Exp. Toxicol. Pathol., 2017, 69 7, 435-441.

74 B. G. Cha, H.-G. Jeong, D.-W. Kang, M.-J. Nam, C. K. Kim, D. Y. Kim, I.-Y. Choi, S. K. Ki, S. I. Kim, J. h. Han, J. Kim and S.-H. Lee, Nano Res., 2018, 11, 3582-3592.
75 Y. Wang, H.-J. Su and S.-D. Wang, Ceram. Int., 2019, 45, 15199-15204.

76 P. K. Mishra, A. Saxena, A. S. Rawat, P. K. Dixit, R. Kumar and P. K. Rai, Environ. Prog. Sustainable Energy, 2018, 37, 221-231.

77 K. Sakthiraj and B. Karthikeyan, Appl. Phys. A: Mater. Sci. Process., 2019, 126, 52.

78 S. Tsunekawa, J.-T. Wang, Y. Kawazoe and A. Kasuya, J. Appl. Phys., 2003, 94, 3654-3656.

79 M. G. Sujana, K. K. Chattopadyay and S. Anand, Appl. Surf. Sci., 2008, 254, 7405-7409.

80 Y.-P. Lan, H. Y. Sohn, Y. Mohassab, Q. Liu and B. Xu, J. Am. Ceram. Soc., 2017, 100, 1863-1875.

81 J. Calvache-Muñoz, F. A. Prado and J. E. Rodríguez-Páez, Colloids Surf., A, 2017, 529, 146-159.

82 I. Trenque, G. C. Magnano, M. A. Bolzinger, L. Roiban, F. Chaput, I. Pitault, S. Briançon, T. Devers, K. MasenelliVarlot, M. Bugnet and D. Amans, Phys. Chem. Chem. Phys., 2019, 21, 5455-5465.

83 G. Balakrishnan, C. M. Raghavan, C. Ghosh, R. Divakar, E. Mohandas, J. I. Song, S. I. Bae and T. Gyu Kim, Ceram. Int., 2013, 39, 8327-8333.

84 M. M. Ali, H. S. Mahdi, A. Parveen and A. Azam, AIP Conf. Proc., 2018, 1953, 030044.

85 J. Tolasz, J. Henych, M. Šťastný, Z. Němečková, M. Š. Slušná, T. Opletal and P. Janoš, RSC Adv., 2020, 10, 14441-14450.

86 B. Elahi, M. Mirzaee, M. Darroudi, R. Kazemi Oskuee, K. Sadri and M. S. Amiri, Ceram. Int., 2019, 45, 4790-4797. 87 Y. W. Hartati, D. R. Komala, D. Hendrati, S. Gaffar, A. Hardianto, Y. Sofiatin and H. H. Bahti, R. Soc. Open Sci, 2021, 8, 202040.

88 A. Iglesias-Mayor, O. Amor-Gutiérrez, A. Costa-García and A. de la Escosura-Muñiz, Sensors, 2019, 19, 5137.

89 H. Huang and J.-J. Zhu, Analyst, 2019, 144, 6789-6811.

90 L. Jiang, Q. Xue, C. Jiao, H. Liu, Y. Zhou, H. Ma and Q. Yang, Anal. Methods, 2018, 10, 2151-2159.

91 F. Meng, H. Miao, J. Shi, Z. Hu, G. Li and Y. Ding, J. Alloys Compd., 2017, 713, 125-131.

92 M. V. Bracamonte, M. Melchionna, A. Giuliani, L. Nasi, C. Tavagnacco, M. Prato and P. Fornasiero, Sens. Actuators, B, 2017, 239, 923-932.

93 B. S. Rohini, H. Nagabhushana, G. P. Darshan, R. B. Basavaraj, S. C. Sharma and R. Sudarmani, Appl. Nanosci., 2017, 7, 815-833.

94 C. J. Neal, A. Gupta, S. Barkam, S. Saraf, S. Das, H. J. Cho and S. Seal, Sci. Rep., 2017, 7, 1324.

95 Y. Kosto, A. Zanut, S. Franchi, Y. Yakovlev, I. Khalakhan, V. Matolín, K. C. Prince, G. Valenti, F. Paolucci and N. Tsud, Appl. Surf. Sci., 2019, 488, 351-359.

96 A. Üğge, D. Koyuncu Zeybek and B. Zeybek, J. Electroanal. Chem., 2018, 813, 134-142.

97 T. Iranmanesh, M. M. Foroughi, S. Jahani, M. Shahidi Zandi and H. Hassani Nadiki, Talanta, 2020, 207, 120318.

98 D. Liu, F. Li, D. Yu, J. Yu and Y. Ding, Nanomaterials, 2019, 9, 54 . 
99 A. Iglesias-Mayor, L. Fernández-Murillo, F. J. García-Alonso, A. de la Escosura-Muñiz and A. Costa-García, J. Electroanal. Chem., 2019, 840, 338-342.

100 N. Alizadeh, A. Salimi, T.-K. Sham, P. Bazylewski and G. Fanchini, ACS Omega, 2020, 5, 11883-11894.

101 A. A. Ensafi, R. Noroozi, N. Zandi-Atashbar and B. Rezaei, Sens. Actuators, B, 2017, 245, 980-987.

102 F. Mohammad, T. Arfin and H. A. Al-lohedan, Mater. Chem. Phys., 2019, 229, 117-123.

103 N. S. K. Gowthaman, H. Ngee Lim, V. Balakumar and S. Shankar, Ultrason. Sonochem., 2020, 61, 104828.

104 Y. Xie, X. Tu, X. Ma, Q. Fang, G. Liu, R. Dai, F. Qu, Y. Yu, L. Lu and X. Huang, Microchim. Acta, 2019, 186, 567.

105 G. Manibalan, G. Murugadoss, R. Thangamuthu, P. Ragupathy, R. Mohan Kumar and R. Jayavel, Appl. Surf. Sci., 2018, 456, 104-113.

106 A. R. Rajamani and S. C. Peter, ACS Appl. Nano Mater., 2018, 1, 5148-5157.

107 M. Ibrahim, Y. Temerk and H. Ibrahim, RSC Adv., 2017, 7, 32357-32366.

108 Y.-F. Sun, J.-J. Li, F. Xie, Y. Wei and M. Yang, Sens. Actuators, $B, 2020,320,128355$.

109 S. Liu, Z. Yang, Y. Chang, Y. Chai and R. Yuan, Biosens. Bioelectron., 2018, 119, 170-175.

110 C. Tortolini, P. Bollella, R. Zumpano, G. Favero, F. Mazzei and R. Antiochia, Biosensors, 2018, 8, 108.

111 A. M. Abdel-Raoof, A. H. Abdel-Monem, A. A. Almrasy, T. F. Mohamed, Z. A. Nasr and G. F. Mohamed, J. Electrochem. Soc., 2020, 167, 047502.

112 H. Y. Kim, J. K. Ahn, M. I. Kim, K. S. Park and H. G. Park, Electrochem. Commun., 2019, 99, 5-10.

113 X. Yang, Y. Ouyang, F. Wu, Y. Hu, Y. Ji and Z. Wu, Sens. Actuators, B, 2017, 238, 40-47.

114 S. Mishra, B. Chishti, H. Fouad, H. K. Seo and Z. A. Ansari, Sci. Adv. Mater., 2020, 12, 220-227.

115 N. Lavanya, J. Nizeyimana Claude and C. Sekar, J. Colloid Interface Sci., 2018, 530, 202-211.

116 S. E. Son, E. Ko, V.-K. Tran, W. Hur, H. Choi, H. B. Lee, Y. Park and G. H. Seong, ChemElectroChem, 2019, 6, 4666-4673.

117 A. Kumar, B. Purohit, P. K. Maurya, L. M. Pandey and P. Chandra, Electroanalysis, 2019, 31, 1615-1629.

118 M. Mahmoudpour, J. Ezzati Nazhad Dolatabadi, M. Torbati, A. Pirpour Tazehkand, A. Homayouni-Rad and M. de la Guardia, Biosens. Bioelectron., 2019, 143, 111603.

119 V. Ruiz-Valdepenas Montiel, E. Povedano, E. Vargas, R. M. Torrente-Rodriguez, M. Pedrero, A. J. Reviejo, S. Campuzano and J. M. Pingarron, ACS Sens., 2018, 3, 211-221.
120 D. Zappi, R. Caminiti, G. M. Ingo, C. Sadun, C. Tortolini and M. L. Antonelli, Talanta, 2017, 175, 566-572.

121 Y. Song, Y. Luo, C. Zhu, H. Li, D. Du and Y. Lin, Biosens. Bioelectron., 2016, 76, 195-212.

122 A. Karimi, A. Othman and S. Andreescu, in Methods in Enzymology, ed. C. V. Kumar, Academic Press, 2016, vol. 571, pp. 177-195.

123 M. B. Gumpu, N. Nesakumar, S. Nagarajan, S. Ramanujam, U. M. Krishnan, K. J. Babu and J. B. B. Rayappan, Bull. Environ. Contam. Toxicol., 2017, 98, 662-671.

124 J. Fu, Int. J. Electrochem. Sci., 2018, 9231-9241.

125 C. Esmaeili, P. Norouzi, M. S. Zar, M. Eskandari, F. Faridbod and M. R. Ganjali, J. Electrochem. Soc., 2019, 166, B1630-B1636.

126 N. M. Ahmad, J. Abdullah, N. A. Yusof, Y. Sulaiman, A. H. Ab. Rashid, S. A. Rahman, H. Hanibah and N. Haron, Sens. Lett., 2017, 15, 928-938.

127 D. M. Stanković, M. Ognjanović, M. Jović, V. Cuplić, A. Lesch, H. H. Girault, M. Gavrović Jankulović and B. Antić, Electroanalysis, 2019, 31, 1517-1525.

128 P. Dong, L. Zhu, J. Huang, J. Ren and J. Lei, Biosens. Bioelectron., 2019, 138, 111313.

129 Y. Bi, L. Ye, Y. Mao, L. Wang, H. Qu, J. Liu and L. Zheng, Biosens. Bioelectron., 2019, 140, 111271.

130 A. Fallatah, M. Almomtan and S. Padalkar, ACS Sustainable Chem. Eng., 2019, 7, 8083-8089.

131 F. Li, Y. Li, J. Feng, Y. Dong, P. Wang, L. Chen, Z. Chen, H. Liu and Q. Wei, Biosens. Bioelectron., 2017, 87, 630-637.

132 X. An, X. Shi, H. Zhang, Y. Yao, G. Wang, Q. Yang, L. Xia and X. Sun, New J. Chem., 2020, 44, 1362-1370.

133 W. Li, X. Qiao, C. Hong, C. Ma and Y. Song, Anal. Biochem., 2020, 592, 113566.

134 R. Xu, P. Lu, B. Wu, X. Wang, X. Pang, B. Du, D. Fan and Q. Wei, Sens. Actuators, B, 2018, 274, 349-355.

135 T. Zhang, X. Ren, D. Fan, X. Kuang, H. Wang, D. Wu and Q. Wei, Sens. Actuators, B, 2019, 297, 126800.

136 N. T. Nguyet, L. T. Hai Yen, V. Van Thu, H. lan, T. Trung, P. H. Vuong and P. D. Tam, J. Phys. Chem. Solids, 2018, 115, 18-25.

137 X. Qian, Q. Qu, L. Li, X. Ran, L. Zuo, R. Huang and Q. Wang, Sensors, 2018, 18, 1878.

138 H. Y. Kim, K. S. Park and H. G. Park, Theranostics, 2020, 10, 4507-4514.

139 X. Sun, Y. Jian, H. Wang, S. Ge, M. Yan and J. Yu, ACS Appl. Mater. Interfaces, 2019, 11, 16198-16206.

140 Y. Li, Y. Zhang, F. Li, J. Feng, M. Li, L. Chen and Y. Dong, Biosens. Bioelectron., 2017, 92, 33-39.

141 C. Zhang, J. He, Y. Zhang, J. Chen, Y. Zhao, Y. Niu and C. Yu, Biosens. Bioelectron., 2018, 102, 94-100. 